\title{
Dictynna
}

Dictynna

Revue de poétique latine

$3 \mid 2006$

Varia

\section{La tempesta e il dio (forme editoriali nei Carmina di Orazio)}

Andrea Cucchiarelli

\section{(2) OpenEdition}

Journals

Edizione digitale

URL: http://journals.openedition.org/dictynna/204

DOI: 10.4000/dictynna.204

ISSN: 1765-3142

Notizia bibliografica digitale

Andrea Cucchiarelli, «La tempesta e il dio (forme editoriali nei Carmina di Orazio) », Dictynna [En ligne], 3 | 2006, mis en ligne le 30 novembre 2010, consulté le 10 décembre 2020. URL : http:// journals.openedition.org/dictynna/204; DOI : https://doi.org/10.4000/dictynna.204

Questo documento è stato generato automaticamente il 10 décembre 2020.

\section{(c) (1) (3)}

Les contenus des la revue Dictynna sont mis à disposition selon les termes de la Licence Creative Commons Attribution - Pas d'Utilisation Commerciale - Pas de Modification 4.0 International. 


\title{
La tempesta e il dio (forme editoriali nei Carmina di Orazio)
}

\author{
Andrea Cucchiarelli
}

\section{Il dio e l'inizio}

1 Orazio ha messo un accesissimo impegno nella costruzione del proprio edificio lirico, disponendone struttura e corrispondenze. Già Virgilio, con le sue dieci egloghe, aveva dato un perfetto esempio di libellus in stile ellenistico, che non avrebbe mancato di imporsi come modello alla nascente letteratura augustea. Ma ciò che contraddistingue Orazio, rispetto a Virgilio, ed anche rispetto ad altri autori della sua età (gli elegiaci, ad esempio) è la misura in cui egli volle porre in luce questo impegno editoriale, l'averne fatto ragione poetica. Non si può escludere che abbia contribuito, a questo fine, la precedente esperienza di Orazio come autore satirico, istituzionalmente portato a riflettere sulle convenzioni e sulle forme poetiche: ed è proprio il I libro dei Sermones il volume destinato, nel corpus oraziano, a corrispondere con maggior esattezza al "perfetto" modello decimale delle Bucoliche ${ }^{1}$.

2 Luogo privilegiato, in cui meglio si faccia evidente l'intenzione editoriale (anche la meno accurata), è, per sua stessa natura, l'inizio: pensata e rivista a più riprese, e finalmente approvata da un autore che ha ormai concluso la sua opera, la sequenza di apertura in un libro poetico si misura inevitabilmente con i temi dell'intera raccolta. A questo massimo di valori espressivi corrisponde abitualmente, secondo la tradizione proemiale, il coinvolgimento delle entità divine. L'inizio divino è tanto più atteso in un genere poetico, come quello lirico, che ha tra i suoi principali temi proprio gli dèi (e i figli degli dèi), come sarà lo stesso Orazio a osservare in ars 83-85 Musa dedit fidibus divos puerosque deorum/et pugilem victorem et equum certamine primum/et iuvenum curas et libera vina referre (si noti, nel catalogo, gli dèi al primo posto).

3 Ma Orazio, al suo primo apparire come poeta lirico, sembra voler disattendere le più ovvie aspettative, rescindere quel tradizionale nesso tra il dio e l'inizio. Il carme inaugurale, infatti, non si rivolge ad una figura divina, ma è dedicato all'illustre 
patrono (prosegue cioè il tracciato che già aveva avuto tappa nella prima satira e nel primo epodo): il nome Maecenas apre il primo verso e l'intera raccolta con l'evidenza di un'epigrafe $^{2}$. È soltanto verso la conclusione del carme che ad Orazio sovvengono alcune divinità, nominate in forma di ipotesi, quasi, si direbbe, di sfuggita: ...si neque tibias/Euterpe cohibet nec Polyhymnia/Lesboum refugit tendere barbiton (carm. 1, 1, 32-4). Ancora nel secondo carme, Orazio si astiene dall'invocare la divinità, ma pure la forma innico-invocativa inizia a lasciarvisi distinguere, sebbene sia estesa all'intera cittadinanza: quem vocet divum populus ruentis/imperi rebus? (carm. 1, 2, 25-6). A quell'indiretto quesito (quem vocet...), e al movimento ipotetico-concessivo del carme d'apertura (si neque...), Orazio ha dunque confinato la ritualità divina dell'inizio. Ma la questione di quale dio si debba invocare, se è cruciale per il popolo di Roma, è al tempo stesso estremamente urgente per un poeta che si trovi a principiare la propria opera, a "svolgerne" il volume.

Della struttura editoriale che Orazio ha dato al proprio corpus lirico, in special modo per ciò che riguarda i primi tre libri dei Carmina, si occuperà il presente lavoro, nel tentativo di identificarne i momenti forti, le soglie, i confini e i passaggi. La divinità, per il fatto di essere un soggetto poetico dalla forte evidenza strutturale, collegandosi ai momenti di inizio (e, quindi, di rilancio o di fine), assolverà ad un ruolo prezioso, identificativo. Vedremo come ad essa si intreccino altri temi, si direbbe "ossessivi": quello, in primo luogo, della "tempesta", emblema oraziano del caos e dell'imprevisto, che al principio d'ordine della divinità naturalmente si oppone. Tranne quando entrambi, dio e tempesta, si congiungano potentemente per abbattersi su di una umanità viziosa, perversa.

\section{Dieci carmi e gli dèi di Alceo}

5 Se alla tradizionale invocazione degli dèi Orazio non si è voluto concedere, egli non ha mancato di esprimersi riguardo alla scelta dei propri modelli poetici. Già verso la conclusione del carme d'apertura, a seguire la menzione di Euterpe e Polimnia, tra i lyrici vates vengono individuati i lesbii, con un preciso riferimento, quindi, ad Alceo e Saffo $\left(1,1,34\right.$ Lesboum...barbiton) ${ }^{3}$. Una tale esplicita indicazione non sorprende in un poeta lirico che, come Orazio, opera sui propri modelli seguendo complesse strategie di recuperi e distanziamenti: la memoria dell'antico autore deve essere suscitata in modo tanto più riconoscibile, per poi essere rielaborata e sfumata (al medesimo atteggiamento si ricollega la celebre tecnica del "motto"4). Così già si era mosso l'Orazio delle Satire e, quindi, degli Epodi, nei confronti di Lucilio e di Archiloco.

6 È, dunque, Orazio stesso, nel suo inizio, ad incoraggiare il confronto con i suoi modelli: e sugli inizi dei poeti lesbii, fortunatamente, non siamo privi di informazioni. Riguardo a Saffo, sappiamo che il primo carme dell'edizione alessandrina era l'inno ad Afrodite, in metro saffico (tema e forma così rappresentativi della poetessa). Ma soprattutto su Alceo, e sul suo testo per come esso circolava al tempo di Orazio, deve appuntarsi la nostra indagine ${ }^{5}$. Talvolta, sarà Orazio ad offrire indizi o conferme riguardo al suo predecessore, tanto più utilmente per quei casi in cui i dati alcaici dovessero risultare ipotetici o incerti.

7 Sulla forma editoriale del testo di Alceo, e sulla sua diffusione in età ellenistica e romana, siamo in condizione di stabilire alcuni punti fermi. L'edizione alessandrina dovette presto imporsi come normativa: gli indizi papiracei, uniti alle testimonianze 
erudite, permettono di ricostruirne raggruppamenti e sequenze ${ }^{6}$. Se dunque, come è assai verosimile, il testo di Alceo doveva circolare nella Roma del I sec. a.C. in esemplari corrispondenti al modello alessandrino, ci troviamo nella condizione, privilegiatissima e rara, di poter gettare lo sguardo sullo scrittoio di un autore antico, che, nel caso di Orazio, sappiamo esser stato ben fornito dei grandi exemplaria Graeca7: 1"“Alceo" di cui ricostruiamo sequenze e strutture editoriali è l'“Alceo" che Orazio, e con lui il suo pubblico, avevano sotto gli occhi.

8 Tra le sequenze dell'edizione di Alceo che siamo in grado di ricostruire compare quella iniziale. Ad aprire il primo libro di Alceo era una successione di tre carmi "divini", di cui restano oggi, nell'ordine, i frr. 307 (ad Apollo; strofa alcaica), 308 (a Hermes; strofa saffica), $343 \mathrm{~V}$. (alle Ninfe; asclepiadeo maggiore) ${ }^{8}$. Ad un primo sguardo, potrebbe risultare che Orazio non abbia tenuto conto dell'esempio di Alceo: come abbiamo già visto, infatti, il suo primo carme è dedicato al patrono Mecenate, nei carmi successivi non compaiono "inni" propriamente detti e tantomeno compare, aggiungiamo, la strofa alcaica, che identificava il primo carme di Alceo. Ma, anche in questo evidente distanziamento, la funzione innica è recuperata da Orazio, sebbene in modo indiretto, attraverso il già ricordato quesito del carme 1, 2: quem vocet divum populus ruentis/imperi rebus? (carm. 1, 2, 25-6). La dimensione corale del populus intensifica, anzi, la funzione innica, e si giustifica in un contesto che non sembra potersi acquietare nell'invocazione stereotipata degli dèi: nei Carmina le figure divine insorgono come entità problematiche, e lo stesso Pater Giove vi si affaccia nel suo più terribile ruolo meteorologico'. Con il secondo componimento, i Carmina si proiettano sullo sfondo del disordine morale e cosmico, collegano la divinità alla tempesta in un nodo strettissimo, che, come meglio vedremo, Orazio nel percorso della sua raccolta poetica cercherà di dipanare.

9 Ancora, il dubbio e l'impossibilità vengono nel carme 1, 2 ribattuti da ulteriori quesiti che non possono non restare senza risposta: prece qua fatigent/virgines sanctae minus audientem/carmina Vestam?/cui dabit partis scelus expiandi/Iuppiter? (26-30). A questo punto, dopo aver sollecitato al massimo l'attenzione del lettore, Orazio si decide a nominare un dio proemiale, "finalmente" (tandem). Se con il minaccioso Giove celeste il carme si era aperto, è ad uno tra i suoi figli divini che spetta il ruolo salvifico: tandem venias precamur,/nube candentis umeros amictus,/augur Apollo (30-2). Dunque, è Apollo, che si trova ad essere la prima figura divina propriamente "invocata" (precamur) nella seconda ode, e nell'intero libro I dei Carmina: ed esattamente con un inno ad Apollo, come abbiamo già ricordato, si apriva l'edizione di Alceo $(307,1 \mathrm{~V}$. ). Tra le divinità che successivamente vengono nominate da Orazio, e in posizione di evidenza (l'ultima), non manca di figurare il "secondo" dio di Alceo, cioè Mercurio-Hermes, con cui Orazio esplicitamente identifica il "giovane" Ottaviano: sive mutata iuvenem figura/ales in terris imitaris almae/filius Maiae patiens vocari/Caesaris ultor (41-44) ${ }^{10}$. Dunque, la coppia ApolloHermes, con cui "Alceo" iniziava, viene distribuita da Orazio ai due estremi della serie divina che riempie la seconda metà del suo secondo carme (posizione a sé è quella del principe-dio Ottaviano, su cui il carme si chiude: 45-52). A richiamare l'attenzione del lettore sulla confrontabilità tra i due "secondi carmi" di Alceo ed Orazio è l'identità di metro - per entrambi la strofe saffica ${ }^{11}$.

Che il discorso divino di Orazio non possa esaurirsi con il carme 1, 2 lo mostra, subito dopo, l'inizio della terza ode, che si apre con Venere, protettrice di Cipro, e con i due fratelli di Elena, i Dioscuri (1-2). Ma la presenza divina si ferma all'inizio del 
componimento, che si chiarisce presto essere un propemptikón per Virgilio: nel caso del terzo carme di Orazio la possibilità di un raffronto lirico-alcaico resta confinata al livello della suggestione, $\mathrm{e}$, ad ogni modo, difficilmente può superare i primi due versi ${ }^{12}$. D'altra parte, come meglio vedremo, i Dioscuri di 1, 3, 2 sono essi stessi divinità alcaiche (si intravede allora, piuttosto, la possibilità di un riscontro tematico, se non "editoriale").

11 Dopo il carme 1, 3 la memoria di Alceo, almeno per ciò che ci è dato di poter osservare, si assottiglia ulteriormente. Per trovare un'imitazione, finalmente diretta, dal modello alcaico, il lettore deve pazientare fino al carme 1, 9, che, nelle sue prime due strofe (o forse le prime tre), rielabora assai da vicino un carme alcaico conservatoci da Ateneo, il fr. $338 \mathrm{~V}^{13}$. Ed è con questo carme, quindi alla nona posizione, che fa la sua prima apparizione nel liber il sistema metrico che doveva essere considerato identificante di Alceo, la strofa alcaica: in alcaiche è lo stesso fr. $338 \mathrm{~V}^{14}$. Ma nella sua prima emulazione diretta di Alceo, sia tematica che metrica, Orazio ha deciso di non volgersi alle figure divine, ha preferito piuttosto riprendere dal modello il tema simposiale. Alcuni cruciali dettagli, come il Soratte e l'anfora di vino sabino, riportano l'invenzione poetica al contesto romano di un Orazio diviso tra la città e l'agellus, schivo dei grandi temi della guerra, come già si è rappresentato in carm. 1, 6 Scriberis Vario fortis, e, quindi, in 1, 7 Laudabunt alii.

12 È invece nel carme immediatamente successivo ad 1, 9 che il percorso divino-alcaico seguito da Orazio si aggiunge di un ulteriore (e ancor più preciso) dettaglio. Anche il carme 1, 10 è un'emulazione "diretta" (metro e tema) del modello alcaico, come già, in questo caso, era stato notato dall'esegesi antica: hymnus est in Mercurium, ab Alcaeo lyrico poeta (Porph. ad v. 1) ${ }^{15}$. Ad essere recuperato ora è proprio il grande modello del secondo inno di Alceo, quello a Hermes. Quasi a segnare il raggiungimento di un confine, con il carme 1, 10 il libro I può compiutamente attuare quella funzione innologica che era rimasta soltanto accennata nel carme 1, 2, il "falso inno" ("quasiiniziale") che si concludeva con la duplice figurazione divina di Mercurio-Ottaviano.

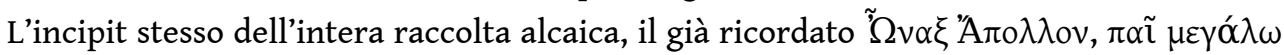
$\Delta$ íos (fr. 307, 1 V.), potrebbe lasciarsi riconoscere, trasferito a Mercurio, nel magni Iovis del carme 1, 10, $5^{16}$. Posti l'uno di seguito all'altro, come in un dittico, i carmi 1, 9 e 1, 10 svelano finalmente, dopo l'elusiva sequenza dei primi tre componimenti ed il silenzio dei successivi cinque, un Orazio che ha deciso di misurarsi con Alceo frontalmente, riprendendone, sebbene così visibilmente "dilazionati", gli iniziali carmi divini ${ }^{17}$. Come nella raccolta di Alceo, l'inno in saffiche a Mercurio/Hermes è preceduto da un componimento in alcaiche: il primo in assoluto nella raccolta di Alceo; il primo in questo metro, anche se "soltanto" in nona posizione, per Orazio.

13 A stabilire i limiti di una tanto articolata intertestualità alcaica (e per renderla più riconoscibile), Orazio è ricorso al numero compiuto, bucolico-virgiliano, del 10, a cui già si era affidato nel suo liber di esordio, il primo dei Sermones ${ }^{18}$. Adesso, nell'esordio di una nuova raccolta, e di un nuovo, più alto, genere poetico, la sequenza 1-10 assume il significato di una parziale compiutezza, se si vuole "liminare" (altri 28 componimenti separano il lettore dalla fine del libro I, e complessivi 78 da quella della raccolta in tre libri $\left.{ }^{19}\right)$. Soltanto, infatti, con il decimo carme, come abbiamo visto, la raccolta presenta la sua prima iterazione del metro (la strofe saffica, già utilizzata nel secondo carme), mentre nei primi nove componimenti Orazio aveva variato costantemente lo schema metrico. Già negli Epodi il confine del dieci era segnato dall'aspetto metrico, ma con un 
procedimento opposto: invece di essere continuamente variato, il metro dei primi dieci epodi restava costante (distici composti da trimetro e dimetro giambici), per essere abbandonato nell'epodo 11, che presenta distici di trimetri giambici ed elegiambi: per un'ulteriore inversione, è nella "seconda parte" (i componimenti 11-17) che gli Epodi non presentano mai la ripetizione del medesimo metro ${ }^{20}$.

Ritagliandosi uno spazio riconoscibile nel continuum del volume, la sequenza dei carmi 1-10 rivendica una propria (parziale) autonomia editoriale. E questo non senza una precisa conseguenza strutturale. Al pari di una monobiblos decimale, Carmina 1, 1-10 si trova a disporre di una posizione esposta nel centro ("al mezzo"): il carme 1, 6, che, come il corrispettivo nel grande modello delle Bucoliche, è esso stesso una "ricusazione" metaletteraria - nos, Agrippa, neque haec dicere nec gravem/Pelidae stomachum cedere nescii eqs. (5-6 ${ }^{21}$. Analogamente, la satira 1, 6, con la sua nuova allocuzione a Mecenate, è strutturalmente qualificata per aprire la seconda metà del I libro dei Sermones, e simile effetto editoriale si può ipotizzare per il carme 3,4 , posto "al mezzo" del ciclo delle Odi romane ${ }^{22}$.

Agli inizi della propria raccolta, Orazio ha seguito una attenta strategia di avvicinamenti e distanze da Alceo: ha recuperato la funzione allocutivo-innica del modello, ma in contesti per così dire "periferici", o, comunque, meno esposti (non senza alcuni oggettivi segnali di confrontabilità, come l'identità metrica tra il carme 1 , 2 e il fr. 308 V.). Questo evasivo gioco di corrispondenze parziali o mancate, ben si spiega con l'atteggiamento di un poeta che si finge esordiente e che si affida al patrono, nella speranza di poter essere incluso tra i canonici $\lambda$ upıkoí della tradizione erudita alessandrina $(1,1,35-36)^{23}$. Quanto difficile fosse ritentare l'inno sulle corde dei poeti lesbii è presupposto dallo stesso carme inaugurale, con le conclusive cautele: si neque tibias/Euterpe cohibet nec Polyhymnia/Lesboum refugit tendere barbiton (33-35) - e, tra tutte le Muse, Polinnia è quella che gli "inni” li porta già nel nome ${ }^{24}$.

\section{La tempesta e il dio (Alceo ed Orazio politici)}

16 Ci è parso che nel carme 1,2 Orazio abbia deliberatamente richiamato l'attenzione del lettore sul problematico statuto della divinità, e, di conseguenza, sulla difficoltà per il poeta lirico di esprimersi nella forma dell'inno. "Quale dio", e "quale preghiera", sono le due questioni inevitabili per chi ha di fronte un vuoto divino, l'assenza della divinità: la stessa Vesta, dea identificante del suolo romano ed emblema della intima quotidianità familiare, più non ascolta i canti delle vergini (27-28 minus audientem/ carmina Vestam). Proprio con l'aver attribuito la funzione innica alla dimensione collettiva del popolo Romano, Orazio ha valorizzato della divinità il significato politico (si rammentino, nel loro insieme, i vv. 21-26). Con piena coerenza, dunque, il carme 1, 2, problematizzato l'atto invocativo, finisce per volgersi ad una figura divina che si identifica con la somma autorità umana: Mercurio-Ottaviano, il "vendicatore di Cesare" (44).

17 Una tale identificazione, tra Ottaviano e il dio, colloca il carme 1, 2 all"interno di quel linguaggio politico che, proseguendo consuetudini già tardo-repubblicane, aveva, nei difficili anni successivi a Filippi, attribuito ai diversi contendenti, e quindi alle loro singole fazioni, alcune specifiche divinità di riferimento. Attraverso il principio divino il linguaggio politico poteva trovare una propria immediata efficacia comunicativa: l"agile Mercurio rappresentava un efficace alter ego divino per il iuvenis Ottaviano, 
mentre Dioniso-Bacco aveva attratto l'immedesimazione di Antonio, e il dio del mare, Nettuno, quella di Sesto Pompeo (ereditata, in realtà, dal padre Pompeo Magno) ${ }^{25}$. Ma, a ben vedere, anche gli altri due dèi con cui Orazio si sforza di spezzare il silenzio divino hanno uno specifico significato politico: il primo ad essere esplicitamente invocato, Apollo, rappresenta, accanto a Mercurio, l'altro grande modello divino del giovane Ottaviano (destinato a divenire preponderante, naturalmente, dopo Azio), mentre Venere è la dea per eccellenza della gens Iulia, e, con essa, dell'intera città. Ancor prima che sia esplicitamente menzionato Cesare (Giulio), e il suo "vendicatore", ben tre dèi hanno dunque orientato il lettore verso la corretta direzione politica ${ }^{26}$.

Con la figura luminosa di un giovane deus, non meglio definito, Virgilio aveva aperto la sua prima egloga, affidando allo sfortunato Melibeo il contrasto di un oscuro destino, l'esilio e la perdita. Nel suo "quasi-inizio" di poeta lirico, Orazio ha voluto esprimere la crisi non, come Virgilio, in un dittico di luce ed ombra, ma evocando uno spazio caotico, omogeneamente incomprensibile, al quale ci si possa sottrarre soltanto attraverso il cambiamento. Per mezzo di una divinità che è antonomasticamente metamorfica, Orazio evoca il tempo passato del diluvio, antefatto mitico ora pericolosamente attuale: Proteo, pastore paradossale in un mondo sconvolto, ribaltato nel rapporto tra acque e terre (7-8 omne cum Proteus pecus egit altos/visere montis), che addirittura vede il Tevere invertire il proprio corso, arrogandosi il ruolo di ultor (13-20). E non altro che una divinità di cui Orazio enfatizza, ancora, la capacità mutevole, potrà aprire una prospettiva rassicurante sul futuro della comunità: sive mutata iuvenem figura/ales in terris imitaris, almae/filius Maiae, patiens vocari/Caesaris ultor (41-44). L'ultima parola del carme esprime, infine, una trasformazione che è divenuta identità: il Caesaris ultor è egli stesso Caesar, guida del popolo romano, fino a quando ancora un mutamento di stato non lo sottrarrà agli uomini, con un nuovo, ed ultimo, "ritorno" (45 serus in caelum redeas $^{27}$.

Questi spostamenti che il testo descrive, tra la dimensione divina e quella umana, esprimono tutto l'impegno e la difficoltà del discorso ideologico che Orazio si sforza di costruire, componendo le contraddizioni, ed al tempo stesso sfruttandone la dolorosa evidenza. Dal dio olimpico che apriva il carme minacciando le sacre rocche della città, l'epiteto pater si sposta verso la chiusa, significativamente, sul giovane Cesare: hic ames dici pater atque princeps (50).

Oltre a quello divino, e ad esso strettamente collegato, c'è un altro tema che acquista, nei Carmina di Orazio, un significato politico: la tempesta. Divinità e tempesta si trovano cioè a costituire i due estremi di una articolata dialettica tra ordine e disordine, tra costruzione e distruzione. Ne è precoce esemplificazione la somma prerogativa del Padre Giove, per come egli è presentato nell'apertura del carme 1, 2 (in quella che, lo ricordiamo, è la prima articolata figurazione divina dei Carmina): controlla la tempesta, può scatenarla fino a portarla alla dimensione del diluvio, ed al contempo può raffrenarla, garantendo al mondo e agli uomini la salvezza ${ }^{28}$. Il complesso intreccio di analogie e significazioni (che un concetto come quello di "allegoria" potrebbe soltanto parzialmente esprimere) tra la sfera naturale, la divinità e l'ordine degli uomini, non manca di svelare, in modo improvviso ed abrupto, il proprio significato civile, nell'amara considerazione del medesimo carme 1, 2: ...civis acuisse ferrum/quo graves Persae melius perirent (21-22). Ancora nel "cittadino Lesbio" Alceo (carm. 1, 32, 5), il modello lirico più specificamente "stasiotico", converrà cercare le risonanze, e i presupposti, di una crisi politica che ha tutta l'evidenza di una metafora. 


\subsection{La luce dei Dioscuri}

21 assume un carattere pluralistico, funziona come intreccio e relazione di testi molteplici, talvolta eterogenei. Proprio da quel primo libro dell'edizione alessandrina, all'inizio del quale compariva la sequenza dei tre inni iniziali (ad Apollo, ad Hermes, alle Ninfe), provengono i frammenti del grande carme allegorico $(208 \mathrm{~V}$.) che ha per oggetto la

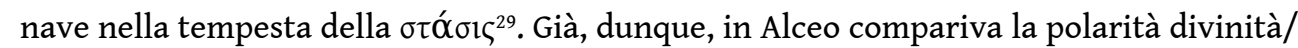
tempesta, distribuita - in una proporzione che a noi riesce impossibile quantificare nella continuità della raccolta, e resa riconoscibile, "compattata", dall'unità libraria (il primo volume dell'edizione). Si impone dunque una prima osservazione. Si può dire, cioè, che Orazio abbia voluto emulare di Alceo, oltre che i singoli testi, l'aspetto editoriale: anche il primo libro dei Carmina, al pari del primo libro dell'Alceo alessandrino, contiene gli dèi alcaici (seppure ironicamente differiti) e un carme allegorico-nautico, 1, 140 navis referent, che ha come principale modello esattamente il fr. $208 \mathrm{~V}$. divinità e la tempesta doveva trovarsi realizzato all'interno del singolo componimento, aggregandosi attorno alle figure salvifiche dei Dioscuri: forse al significato allegoricostasiotico rinviava esplicitamente il testo stesso, oppure era il contesto stasiotico dei componimenti limitrofi a legittimare un'interpretazione allegorica. Il primo carme (34 V.), meglio conservato, si presenta come un inno cletico ai due fratelli divini, dei quali è invocato il soccorso, e cioè la salvifica luce, che, nella terribile notte, possa rischiarare la nera nave (11-12). Nel secondo carme (34A V.), assai più frammentario, i Dioscuri vengono nuovamente invocati, perché raggiungano, sembra di capire, l'isola di Lesbo, designata attraverso il nome del re fondatore Macare (10-11) ${ }^{30}$. In entrambi i carmi la possibilità dell'interpretazione stasiotica trova solido sostegno, rispettivamente,

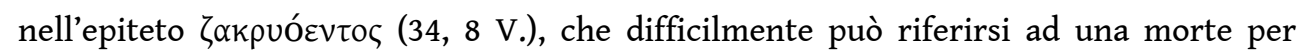

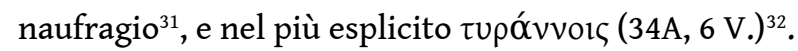

Sullo specifico tema dei Dioscuri, Orazio reagisce alle sollecitazioni del modello alcaico, ancora una volta, con differimenti e scomposizioni. Nel caso della tempesta nel carme 1,2 , è isolato il dettaglio del ferrum rivolto contro i concittadini (v. 21), ma senza che i Dioscuri siano nominati. La possibilità di un confronto con Alceo sembrerebbe farsi inconsistente, se non fosse per la sequenza editoriale predisposta da Orazio: l'immediatamente successivo carme 1,3 si apre infatti con l'invocazione della protezione divina, in un contesto che si scopre essere, gradatamente, marino e nautico. Ed ora, a seguire Venere, signora di Cipro (e tutela dei naviganti) ${ }^{33}$, sono nominati i due fratelli divini, nel loro aspetto luminoso: ...sic fratres Helenae, lucida sidera... (2). La meteorologia minacciosa che apriva il carme 1, 2, con l'imperversare del Pater Giove, si fa nel carme 1, 3 augurio di una serena traversata, che possa esser concessa da un altro, più specifico, pater (quello dei venti: v. 3). Agli occhi del lettore "ingenuo", che già non abbia presente il carme 1, 3, esso per un istante sembrerebbe completare il percorso alcaico evocandone un'altra specifica essenza: il lungo movimento dei vv. 1-4 si appunta infatti sulla parola, navis, che apre il v. 5. Ma questa si svela immediatamente come letterale imbarcazione che trasporta il poeta Virgilio, sul nome del quale il lungo periodo trova l'ultima, chiarificatrice, parola (e la sua pausa metrico-ritmica). Per 
incontrare una vera e propria nave allegorico-stasiotica, il lettore dovrà attendere ancora, fino al carme 1, 14, che la presenta, senza più esitazioni, in incipit (O navis).

Dispiegandosi, dunque, nelle forme del propemptikón, il carme 1, 3 sembra sottrarsi alla meteorologia politica del carme 1,2. Ma pure, a quella angosciosa teodicea esso sembra

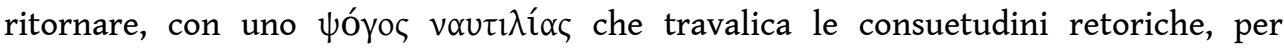
mobilitare i più profondi concetti morali: l'empietà delle navi che attraversano il mare vietato dagli dèi (21-24); l'audacia degli uomini che rovinano nel nefas (25-26); gli exempla mitici, presentati come negativi, di Prometeo (27-33), di Dedalo (34-35), e, addirittura, di Ercole, cui viene rimproverata la violazione dell'Acheronte (36) ${ }^{34}$. È come se anche in questo carme lo scenario angoscioso prospettato dal carme 1, 2 ossessionasse il poeta. Quando gli uomini, in chiusura, sono equiparati a empi Titani o Giganti che attentino al cielo (38 caelum ipsum petimus stultitia), il lettore si sente trascinato all'indietro di quasi due interi carmi: e non manca di ricomparire la figura punitiva di Giove folgorante, che ora chiude il carme 1, 3, come già aveva aperto $1,2-\ldots$ neque/per nostrum patimur scelus/iracunda Iovem ponere fulmina (38-40) ${ }^{35}$. Lo scelus del carme 1, 2, 29 non è stato espiato, e sembra che ad Orazio non possa riuscire di scrivere un sereno propemptikón.

Crediamo che la sequenza dei primi tre carmi di Orazio, evitando la forma rassicurante dell'inno (che caratterizzava invece le prime tre posizioni della raccolta di Alceo), ed anzi proiettando nella dimensione divina le ansie della Storia umana, lasci il lettore inquieto, emotivamente stimolato a proseguire nella lettura. Ma, superato il confine del tre, Orazio si concede un'improvvisa apertura: dopo gli inverni, le nevi e la grandine del carme 1,2, dopo i fulmini di Giove che chiudono il carme 1, 3 (così minacciosi anche soltanto per Virgilio prossimo ad imbarcarsi), il carme 1, 4 è illuminato dallo schiudersi di una serena primavera. Il dolce Favonio, nell'avvicendarsi regolato della stagione (1, 4, 1 grata vice veris), fa sentire come ormai lontani quei venti che, nell'inizio del carme precedente, dovevano essere trattenuti a forza (1, 3, 4 obstrictis alis), e ogni pericolo nautico sembra ormai scomparso: trahuntque siccas machinae carinas $(1,4,2)^{36}$. L'incipit solvitur rimarca l'allentarsi delle tensioni, e rinvia, ancora una volta, ad $\mathrm{Alceo}^{37}$, in questo carme che varia su di un tono lieve, e quasi esorcizza, le tensioni accumulate nei tre precedenti: forse per questo vi compaiono, come già abbiamo potuto osservare, le uniche figure divine iniziali di Alceo che ancora Orazio non abbia nominato - le Ninfe, nel loro più dolce ruolo, compagne di Venere e delle Grazie (ibid. 6 iunctaeque Nymphis Gratiae decentes).

Nella direzione segnata dal carme 1, 4, il libro I prosegue. Dunque, il successivo carme 1, 5 si concentra sul tema dell'eros (già introdotto dal giovane Licida su cui si è chiuso 1 , 4); "ricusatore" dei grandi temi è 1, 6, ed analogamente 1, 7 (con la memorabile chiusa "nautica", che si inserisce in un contesto oscuro di ansie: cras ingens iterabimus aequor [32]); all'eros ancora è dedicato 1,8 , che si apre nel nome della crudele Lydia. Il carme 1,9 , con il suo riconoscibile modello alcaico (fr. $338 \mathrm{~V}$.) ${ }^{38}$, segna un contrasto: lo "sciogliersi" della primavera, la luce calda del sole (cf. 1, 8, 4), ora è sostituita da un nuovo "contrarsi", quello del ghiaccio invernale - ...geluque/flumina constiterint acuto (3-4). Soltanto nella dimensione intima del convivio, è possibile, di nuovo, "scioglierlo" (si fa percepibile, nel tema radicale, il solvitur di 1,4): dissolve frigus ligna super foco/large reponens (5-6). Sembra che il libro stesso di Orazio, nel suo svolgersi, voglia riprodurre quel principio di avvicendamento, "ritmico", che occupa il centro, concettuale e strutturale, del carme 1,7 - modello di ordine poetico oltreché morale: albus ut obscuro 
deterget nubila caelo/saepe Notus neque parturit imbris/perpetuo, sic tu sapiens finire memento/tristitiam vitaeque labores/molli, Plance, mero (15-19).

Nella dimensione protetta del carme 1, 9 esclusivamente come minaccia lontana può comparire la tempesta marina: ma, anche qui, in diretta connessione con gli dèi, e non

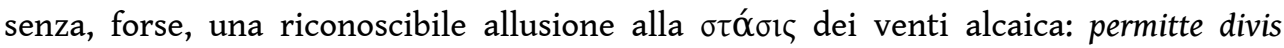
cetera, qui simul/stravere ventos aequore fervido/deproeliantis, nec cupressi/nec veteres agitantur orni (9-12) ${ }^{39}$. Sarà necessario che Orazio superi il limite del dieci, e introduca la sua prima compiuta imitazione di Alceo (l'inno al civilizzatore Mercurio), perché egli possa tornare alla tematica civile della tempesta - e alla coppia divina riconoscibilmente alcaica, i Dioscuri ${ }^{40}$. Nel carme 1, 12, finalmente, l'immagine dei due fratelli divini che, all'improvviso, placano i venti e il mare, può essere recuperata e resa esplicita: quorum simul alba nautis/stella refulsit,/defluit saxis agitatus umor,/concidunt venti fugiuntque nubes/et minax, quod sic voluere, ponto/unda recumbit $(1,12,27-32)^{41}$. E il dettaglio della luce salvifica richiama esattamente l'archetipo innico di Alceo, il fr. 34

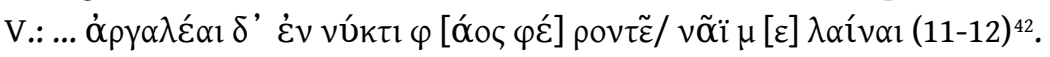

La traccia alcaica, riguardo ai Dioscuri, viene dunque accennata e poi dispersa nella prima sequenza della raccolta oraziana, per poi essere ritrovata: dopo i richiami del carme 1, 3, e del carme 1, 9, è soltanto nel carme 1, 12 che i figli di Leda assumono pienamente il ruolo, che avevano in Alceo, di protettori dalle tempeste. Questo specifico nesso $(1,3-1,9-1,12)$ si iscrive in realtà all'interno di un più ampio meccanismo di corrispondenze e ampliamenti che lega il carme 1, 12 alla precedente sezione del libro I. Si può forse dire che il superamento del dieci ha significato la necessità di un rilancio nel liber, e al tempo stesso un sintetico sguardo all'indietro: tanto più che con il carme 1,12 si ha una nuova ripetizione della strofe saffica e del tema innologico, ovvero un "prolungamento" di un altro nesso, quello che connette il carme 1,2 al carme 1,10 (come meglio vedremo più avanti, Orazio ha voluto "sfrangiare", all'inizio del libro I ed anche nella sua prosecuzione, il confine del dieci).

Interpretato come ripresa, e completamento, del carme 1, 2, il carme 1, 12 si spiega nel suo recupero di quell'Alceo innografico-politico, che ancora non era stato oggetto di imitazione: dopo il carme 1, 10, esplicita "riscrittura" del secondo inno alcaico, il carme 1,12 può puntare direttamente verso le divinità, meteorologico-politiche, dei Dioscuri. E la stessa interpretabilità allegorico-politica del modello alcaico riesce confermata da Orazio. "Politico", infatti, è il contesto del carme 1, 12, che colloca i Dioscuri nello snodo tra la serie degli esempi divini (vv. 13-24: Giove, Pallade, Libero, Artemide, Febo) e la serie degli esempi eroici e romani (33-48: da Romolo al sidus Iulium, simbolo dei due Cesari). Assieme ad Ercole, i Dioscuri rappresenteranno in altri luoghi lirici di Orazio il paradigma ideale dell'uomo che, grazie alla propria virtù, viene ammesso tra gli dèi olimpii - e, dunque, la prefigurazione di Augusto divinizzato ${ }^{43}$.

Nel carme 1, 2 il giovane dio Mercurio-Ottaviano, chiudendo il componimento, aveva rappresentato un'argine alla forza di Giove che minacciosamente ne occupava i primi versi (nonostante che le "irose saette" del dio ricomparissero "poi" nella chiusa del carme 1, 3). Dopo il "vero inno" alcaico, quello a Mercurio del carme 1, 10, Orazio torna alla questione della divinità, ancora legandola alle facoltà meteorologiche: anche all'interno del carme 1, 12, Giove, comparendovi obbligatoriamente per primo, ha il ruolo di regolatore delle stagioni, sul mare e sulla terra (vv. 13-18) ${ }^{44}$. Ma, questa volta, nella parte finale del carme, sembra che tra la somma divinità e Cesare si sia stabilita una profonda consonanza: al "nato da Saturno" è infatti affidata la tutela del principe - 
tibi cura magni/Caesaris fatis data: tu secundo/Caesare regnes (50-52). Con un suo analogo umano (e divino) sulla terra, Giove, finalmente, non dovrebbe avere più ragioni di essere in collera con l'umanità intera: i suoi fulmini si abbatteranno soltanto sui boschi profanati da atti empi - tu gravi curru quaties Olympum,/tu parum castis inimica mittes/ fulmina lucis (58-60). Nella chiusa del carme 1, 12 si saldano le due figure, Giove e Cesare, che incorniciavano, a contrasto, il carme 1,2 . Il poeta Orazio ha compiuto una sua prima evoluzione, ha dato una prima prova di sé al lettore, sul tema, cruciale, della divinità: ha posto un problema (la collera di Giove contro Roma), ne ha offerto una soluzione (il doppio governo, tra il cielo e la terra, di Giove e del principe). Ancora posti in una posizione editorialmente esposta - in chiusa come nel carme 1,3-, questa volta i fulmini di Giove appaiono meno minacciosi.

Il continuum editoriale si fa mezzo privilegiato per esprimere nella sua complessità un discorso ideologico che non manca di coinvolgere modelli, autorità e competenze: il carme 1, 10 qualifica il poeta Orazio come compiuto emulo di Alceo (a conferma di uno studiatissimo equilibrio, il dio Mercurio, che è protagonista del carme 1,10 , non è nominato in 1,12 , che si concentra su altri dèi). La scelta metrico-ritmica rimarca la pertinenza: ricordiamo, ancora un'ultima volta, che 1,$2 ; 1,10 ; 1,12$ sono gli unici tre carmi, nel gruppo dei primi venti, ad utilizzare la strofe saffica (se si esclude il “conclusivo" 1,20 , seconda soglia decimale del liber $)^{45}$.

\subsection{La nave e gli dèi infranti}

Con il carme 1, 12 Orazio ha completato una sua prima messa a punto del nesso tra la tempesta e il dio. Utilizzando elementi e suggestioni in special modo alcaici, il libro I, già nelle sue sequenze iniziali, ha costruito un articolato linguaggio di immagini, metafore e potenzialità allegoriche, di cui il lettore può disporre nel proseguire il proprio percorso all'interno dei Carmina. La traccia di Alceo, e degli dèi di Alceo, viene ripresa e dissimulata, ma resta costante nel gioco intermittente delle alternanze: come abbiamo visto, essa si percepisce in 1, 3, e, quindi, nel "trittico" di 1, 9;1, 10;1, 12, con l'inserzione, extra-alcaica e personalistica, di 1, 11 (in cui gli inverni e Giove sono riportati alla dimensione individuale dell'esistere ${ }^{46}$ ). Subito dopo, una seconda inserzione: quella del carme 1,13, in cui Orazio si misura con l'altro grande autore della lirica lesbia, Saffo, e, infine, il carme 1, 14, che contiene un'ulteriore, evidente, riscrittura alcaica.

Come già nel carme 1, 3, la nave del carme 1, 14 rappresenta la "cellula di resistenza" dell'individuo, altrimenti in balia del mare e della tempesta, ma essa acquista ora, dal contesto alcaico, un preciso significato allegorico: espressione di socialità ristretta, rinvia ai valori politici di un gruppo (o di un individuo?) che il dissidio civile rischia di travolgere ${ }^{47}$. Anche qui, nel contesto di una tempesta (allegorica) che minaccia la nave, della quale il poeta segue con ansia il destino (18 nunc desiderium curaque non levis), ricompaiono gli dèi: non tibi sunt integra lintea,/non di, quos iterum pressa voces malo (9-10) ${ }^{48}$. Gli dèi non più "integri", su cui la nave non può più contare, non sono soltanto degli oggetti nautico-marinari (immagini divine come, ad esempio, delle "polene"), ma partecipano essi stessi dell'allegoria, rappresentano lo sfavore di forze divine che sono, al tempo stesso, politiche e "terrene". Il carme 1, 14 non si sottrae al binomio diotempesta, che però completa con una divinità che non è adeguata ad arginare la tempesta: non vi compare una forza divina amica che sappia acquietare i "venti in 
lotta" (1, 9, 9-11), non vi compaiono i Dioscuri dei due inni di Alceo (e del carme 1, 12), né il giovane dio "mercuriale", il salvifico Ottaviano.

A conferma dell'intenzione di Orazio è il fatto che, a quanto possiamo vedere, dalle diverse allegorie nautiche di Alceo restava assente un qualunque riferimento alla dimensione divina. Esattamente questo dettaglio, che è tra quelli immessi da Orazio per individuare la propria allegoria rispetto al modello, verrà recuperato, contrastivamente, nella diversa situazione del carme 2, 7 (simmetrico, e risolutivo, in rapporto a $1,14^{49}$ ). A segnare il destino di Orazio, rispetto all'amico Pompeo ricacciato in alto mare dalle onde della guerra civile, sarà nel libro II l'intervento, all'indomani di Filippi, di un benevolo Mercurio: ...sed me per hostis Mercurius celer/denso paventem sustulit aere,/te rursus in bellum resorbens/unda fretis tulit aestuosis (2, 7, 13-16) - Mercurio, il dio che il libro I ha mostrato essere il corrispettivo divino del giovane principe, ed al contempo uno tra gli dèi di Alceo ${ }^{50}$.

\subsection{La nave e la guerra, il simposio e la nausea (epod. 9, 35)}

Il nesso tra le due allegorie di 1,14 e di 2, 7 rende evidente una polarità situazionale, quella tra la nave e il simposio, che già era insita nell'opera di Alceo (e diveniva esplicita, ad esempio, in un frammento come il $73 \mathrm{~V}$.): nel carme 2, 7, infatti, la simposialità, rievocata per il tempo anteriore a Filippi (vv. 5-8), quindi impedita dall'onda stasiotica, si attua finalmente nel rasserenato presente dei vv. 17-28. All'aspetto dionisiaco-simposiale di Alceo, Orazio non manca di rinviare nel corso del libro I, attraverso il "motto" del carme 1, 18 (cf. 342 V.), mentre nel carme 1, 32 la nave e il vino vengono esplicitamente ricondotti, tra diversi altri momenti (soprattutto erotici), alla figura dell'auctor: ...tamen inter arma/sive iactatam religarat udo/litore navim,/ Liberum et Musas Veneremque.../...canebat (6-10) ${ }^{51}$. Il vino e la memoria di Alceo torneranno, connessi al tema politico del "tiranno", nel carme 1, 37 - e per celebrare la grande vittoria nel decisivo scontro, "nautico", tra le opposte flotte: Nunc est bibendum, nunc pede libero/pulsanda tellus (1-2). Alla sconfitta Cleopatra, ubriaca di esotico vino nel mezzo della battaglia, è concesso di attuare soltanto in forma di perversione il rapporto guerriero, ed alcaico, tra il bere e la nave: sed minuit furorem/vix una sospes navis ab ignibus,/mentemque lymphatam Mareotico/redegit in veros timores/Caesar (12-16).

È naturale, da un lato, che la nave si contrapponga al simposio: essa rappresenta l'impegno, l'innesco dell'impresa, il vettore che trasporta gli uomini verso il destino della guerra. Ma essa è anche il punto di coesione per il gruppo, la parete che separa dal mare, che protegge dalla tempesta meteorologica (e politica): per questa ragione può scoprirsi analoga allo spazio simposiale, può condividerne immagini e suggestioni ${ }^{52}$. A bordo della nave, come nel simposio, il gruppo si raccoglie e si isola, ha una barriera da opporre alla dimensione esterna della natura e della divinità. Una tale complessa interazione va tenuta presente in fase interpretativa, può riuscire preziosa per comprendere quelle che altrimenti resterebbero ambiguità difficilmente risolvibili: è il caso, come vedremo, del discusso fluentem nauseam (epod. 9, 35). Altrettanto decisivo, come cercheremo di mostrare, è uno sguardo "sinottico", che collochi il singolo testo (e la singola difficoltà) all'interno di una rete di confronti che, dagli Epodi, giunge fino ai Carmina - sulla confrontabilità tra il "nuovo" registro lirico e il "vecchio" ethos giambico non manca del resto di richiamare l'attenzione lo stesso Orazio: me quoque 
pectoris/temptavit in dulci iuventa/fervor et in celeris iambos/misit furentem (carm. 1, 13, 22-5).

Di per sé, la nave è un punto di intersezione rilevante tra le due distinte dimensioni dei Carmina e degli Epodi, appartiene a quel ristretto gruppo di elementi tematici su cui Orazio imposta confronti e differenze. Già i due principali auctores dell'Orazio giambico e lirico, Archiloco e Alceo, entrambi poeti "nautici" e guerrieri, sperimentavano su di essa una confrontabilità (allegorica) che non mancò di essere osservata, e disposta "in parallelo", dal retore Eraclito, nel noto luogo di All. 5.

È appunto un "andare per mare" (Ibis) ad aprire la raccolta archilochea, gli Epodi:ma soggetto ne è Mecenate, e non il poeta. Diversamente dall'auctor Archiloco (ma anche da Alceo), l'Orazio degli Epodi si colloca in una posizione marginale rispetto al viaggio e allo scontro nautici. La conseguente distanza, tra Orazio e Mecenate, accende il valore dell'amicizia (si noti l'amice del v. 2, e il comes del v. 17, nei quali non si sbaglierebbe a percepire una risonanza del greco $\dot{\varepsilon} \tau \alpha \tilde{i} \rho \circ)$ ): inattuabile risulta la dimensione dell'otium, che non può essere "dolce" ad Orazio in assenza dell'illustre amico - utrumne iussi persequemur otium,/non dulce ni tecum simul,/an hunc laborem eqs. (7-8). In sede giambica, e all'esordio della collezione, viene dunque prefigurato, seppure negativamente, quel nesso tra tema nautico e simposialità che abbiamo visto collegare il carme $1,14 \mathrm{al}$ carme 2, 7: Epodi e Carmina, sovrapponendosi,definiscono con coerenza i valori sociali e letterari del "gruppo" cui Orazio appartiene, e della sua stessa persona letteraria. Nel carme 1, 14 Orazio non sembra collocarsi, alcaicamente, all'interno della nave, ma piuttosto sulla riva ${ }^{53}$, mentre nel carme 2, 7 l'unda della guerra civile riporta in alto mare l'amico Pompeo, ma non Orazio: nell'epodo 1 è a Mecenate che spetta il compito di prendere il ruolo dell'Archiloco marinaio e guerriero, mentre ad Orazio resta, sembrerebbe, l'ansia per l'amico nel perigliio ${ }^{54}$.

Su questi presupposti, tanto precocemente stabiliti nel liber giambico, si chiarisce perché anche nell'epodo di Azio, che segna la destinazione logica e storica (oltreché geografica) dell'epodo 1, l'ansia per la vittoria ancora incerta debba impedire la simposialità: Quando repostum Caecubum ad festas dapes/victore laetus Caesare/tecum sub alta - sic Iovi gratum - domo,/beate Maecenas, bibam eqs.? (1-4). La domanda esprime una impossibilità, che gli Epodi non sembrano poter sciogliere, ancorati come sono ad una cronologia "alta", di cui qui l'epodo 9 segna il più avanzato limite (si pensi all'epodo 16, su cui grava, "ancora", la nube di una nuova guerra civile). È soltanto nella successiva raccolta lirica che Orazio può registrare il trionfo, e può finalmente sciogliere ogni riserva, dare una risposta alla domanda con cui si era aperto l'epodo 9: Nunc est bibendum, nunc pede libero/pulsanda tellus, nunc Saliaribus/ornare pulvinar deorum/tempus erat dapibus, sodales $(1,37,1-4)$. Nell'iterazione del nunc sembra cogliersi l'enfasi di una risposta tanto lungamente attesa, ma è la strofa successiva a rendere ancor più esplicito il nesso: antehac nefas depromere Caecubum/cellis avitis eqs. (5-6). Il Cecubo, evidentemente di qualità superiore perché conservato nelle "cantine degli avi", corrisponde al repostum Caecubum su cui si era a suo tempo aperto l'epodo $9^{55}$.

Convergendo, il tema simposiale e quello politico liberano un'energia che giunge all'eccesso dionisiaco: il carme 1, 37, che chiude il percorso alcaico del libro I con una

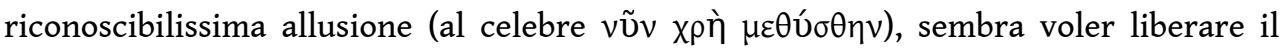
poeta ed il lettore dalle ansie politiche accumulate a partire dal carme 1, 2, e riaccese dall'allegorico-alcaico carme 1, 14 (e, come abbiamo visto, radicate già negli Epodi): una

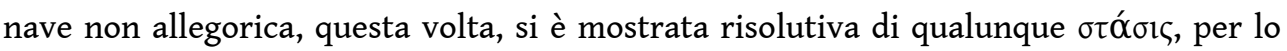


sfacelo della flotta egiziana (12-13 sed minuit furorem/vix una sospes navis ab ignibus). Il ristabilirsi di una completa, positiva, simposialità, a conclusione del percorso tracciato da Orazio nel I libro, individua in Cleopatra un anti-modello: la regina, infatti, nell'atto della ritirata, viene descritta come "resa folle dal vino Mareotico" - ...mentemque lymphatam Mareotico/redegit in veros timores Caesar (14-15). L'ubriachezza, presentata come sua caratteristica permanente, e metaforica (cf. 11-12 fortunaque dulci/ebria), la possiede evidentemente ancor prima della risoluzione della battaglia, ne determina gli atti e il pensiero. Dunque, il triplice nunc iniziale si rivela esser detto in contrasto anche con la precoce (o mai interrotta) ebbrezza di Cleopatra ${ }^{56}$.

41 Una tale opposizione tra un modello di simposialità "corretta" e un modello di simposialità "non-corretta", che trova note risonanze nel contesto della propaganda ottavianea, si rende necessaria anche nell'interpretazione di un dettaglio che, altrimenti, resterebbe ambiguo, e che infatti, come anticipavamo, è al centro di una dibattutissima ed annosa discussione: il fluentem nauseam di epod. 9, 35. Se Orazio si descrivesse in preda alla nausea data dall'eccessivo bere, secondo quanto sostenuto da E. Fraenkel (1957), p. 73, egli si assimilerebbe alla "scorretta" simposialità, contravverrebbe al modello positivo, "controllato", di simposialità. I vini presi in considerazione nei vv. 33-36 servono soltanto a lenire le ansie, alla fine di una giornata cruciale ma non ancora decisiva, giungono dopo le fasi decisive della battaglia (dunque, Orazio non può già essere ubriaco). Il Cecubo del v. 36 ha uno scopo medicinale, e non può identificarsi con il Cecubo "d'annata" che apre il componimento, e che si colloca nella cornice dei festeggiamenti, verosimilmente a Roma, per lo sperato trionfo ${ }^{57}$.

Non possiamo dire se davvero Orazio sia stato o no presente ad Azio. Ma l'epodo 9 presuppone un poeta che "vede" le diverse fasi della battaglia, le commenta, resta nell'ansia di una vittoria non ancora completa. La sua posizione marginale, l'atteggiamento di puro spettatore, già del resto avanzato nell'epodo 1, hanno comprensibilmente indotto gli interpreti a dubitare della sua effettiva presenza sul luogo dello scontro. Ma forse la marginalità di Orazio si può spiegare con quell'ironia che contraddistingue il poeta (e la sua persona letteraria) al momento di entrare in contatto con i "grandi eventi", le magnae res della politica. Un disagio come il "mal di mare" (nausea) rientra nel profilo di un poeta giambico (post-archilocheo) che si è definito, nel contesto della partenza per Azio (di Mecenate), imbellis ac firmus parum (epod. 1, 16), e che già al tempo dell'ambasceria a Brindisi - un viaggio assai meno pericoloso - non aveva mancato di preoccuparsi della propria lippitudo all'arrivo di Mecenate e degli altri importanti uomini politici, e di ritirarsi a riposare, per ragioni ancora "oftalmiche", quando lo stesso Mecenate aveva deciso di giocare alla palla (sat. $1,5,30-1 ; 48-9)^{58}$.

43 È forse utile aggiungere ancora almeno una considerazione. L'ironia di un poeta che, nelle Satire come negli Epodi (talvolta ancora nei Carmina), si rappresenta in ruoli che lo rivelano fisicamente inadeguato, si trova, almeno parzialmente, a collimare con l'atteggiamento distaccato dell'epicureo, che, come Lucrezio, è dalla riva che assiste ai grandi o meno grandi perigli nautici. Se nel carme 1, 14 Orazio sembra osservare la nave dalla riva, spettatore dell'imminente naufragio, nell'epodo 9 egli attua quanto Lucrezio aveva scritto pochi versi più avanti nel suo memorabile proemio: suave etiam belli certamina magna tueri/per campos instructa tua sine parte pericli (5-6); ed anche fervere cum videas classem lateque vagari (43a). Sono, queste, suggestioni riposte, in cui potrebbe esprimersi il margine di libertà, irriducibile, che Orazio si è concesso nei rapporti con i 
suoi potenti amici (almeno nel gioco delle memorie letterarie e filosofiche). Il totale distacco emotivo, epicureo, da vicende che riguardano Mecenate e l'intero popolo di Roma, non deve essere nemmeno concepibile: sono stati d'animo opposti - desiderio, ansia, timore - ad essere espressi da Orazio, con un'insistenza, che è certamente sospetta, forse compensativa.

Già nel passaggio dalle Satire agli Epodi avveniva che le due distinte forme letterarie, e le due distinte opere, si incrociassero in un gioco di rimandi: tra le più evidenti, ad esempio, è l'intersezione giocata sul nome di Canidia. Analoghi effetti sono osservabili tra gli Epodi e i Carmina, in special modo il I libro. Ad un confronto con il distinto registro lirico sembra indirizzare il medesimo epodo 9, attraverso il dettaglio della lyra, chiamata a celebrare, mista ai flauti, la definitiva vittoria (con un "canto dorico"): sonante mixtum tibiis carmen lyra,/hac Dorium, illis barbarum (5-6). Anche per questa via, inevitabilmente torniamo al carme 1, 37: la vera risposta lirica ai desideri, anche “musicali", dell'epodo $9^{59}$.

Forse, a facilitare il dialogo tra l'epodo e il carme (o a esserne conseguenza) è anche una collocazione editoriale in qualche misura raffrontabile: l'epodo 9 immediatamente a precedere l'ultimo componimento della sequenza omometrica (epodi 1-10); il carme 1, 37 all'estremità del libro I, subito prima del conclusivo 1, 38. Che il tema di Azio possa occupare una posizione di "cornice" (o, meglio, "pre-cornice"), non sorprende: il libro degli Epodi si era aperto con un imminente futuro di guerra (nautica), e gli stessi Carmina, nel secondo componimento, post-proemiale, si erano aperti sull'oscuro futuro del popolo romano.

\section{La decina e oltre: dèi e "confini editoriali" nei Carmina}

La misura del dieci, da Orazio tenuta diversamente presente sia nei Sermones che negli Epodi, ci è apparsa, all'inizio del libro I dei Carmina, connessa al tema della divinità: il "difficile" avvio innico del libro, problematizzato da Orazio, si è risolto nell'imitazione alcaica del carme 1,10 , per poi essere perfezionato dal carme 1,12 . Abbiamo visto come sia connesso al tema della divinità, in rapporto talvolta oppositivo, l'elemento meteorologico (la "tempesta"), emblema dell'evento incontrollabile, eppure decisivo sul destino dell'uomo. Intrecciandosi o separandosi, e finalmente componendosi nella forma rassicurante dell'inno o della preghiera (i Dioscuri del carme 1,12), divinità e tempesta hanno stabilito una ricorsività nel continuum editoriale, hanno potenziato del libro la leggibilità, identificandone luoghi forti e punti di snodo. La forma metrica, nelle sue alternanze e, soprattutto, nelle sue ripetizioni, rimarca le strutture editoriali: i numeri e gli animi degli antichi modelli si uniscono alle res per stabilire ariose ma riconoscibili cadenze - quasi che la ritmicità propria del verso, e della strofe, potesse replicarsi nella lettura continuata dei Carmina, potesse mutarsi nella "ritmicità", combinata, di metri e temi. Oppure, se si preferisce, la ricerca della variatio, attiva sia al livello metrico che a quello tematico ${ }^{60}$, finisce inevitabilmente per individuare delle “invarianti": per il fatto stesso di stabilire delle iterazioni, essa deve riposare su alcuni definiti luoghi, identificabili, del liber.

Se tutto questo è vero, si dovrebbero poter ritrovare analoghe strutture editoriali nel seguito dei Carmina: di ciò ci occuperemo appunto nei prossimi paragrafi ${ }^{61}$. 


\section{1 Oltre la prima decina (ancora nel libro I)}

sequenza decimale (post-virgiliana): come abbiamo visto, esso allerta il lettore, introducendo la prima iterazione del metro nel liber e realizza finalmente l'istanza innografica (e alcaica), abitualmente proemiale. I suoi sono numeri equilibratissimi: cinque strofe, per un totale di venti versi (venti, lo ricordiamo, saranno i carmi del libro II, e venti le epistole del libro I). E sugli dèi, nella speculare simmetria di alto/basso, superi/inferi, esso si conclude: superis deorum/gratus et imis (carm. 1, 10, 19-20)62. Ma pure, una tale perfezione di "limite" sembra essere mobilitata dalla prosecuzione del liber: infatti, come abbiamo più volte ripetuto, è nel carme 1,12 che Orazio riprende ancora una volta, e compiutamente, la problematica innografica, replicando quel metro saffico che aveva individuato il nesso tra 1,2 e 1, 10. Anche il carme 1, 11 sembra volersi agganciare alla sequenza che lo precede: i suoi asclepiadei maggiori introducono una varietà del metro asclepiadeo non ancora rappresentata nel libro I, ed il tema stesso del carpe diem si ricollega direttamente ai precedenti carmi 7 e 9, come non si è mancato di osservare $^{63}$.

Sembra, dunque, che Orazio abbia introdotto un elemento di mobilità nell'individuare il primo confine editoriale della raccolta: è come se la soglia del dieci, per così dire, apparisse "sfrangiata", non si esaurisse ad un solo componimento, ma ne abbracciasse più d'uno (non una linea di demarcazione netta, ma un" "area” di confine). L'effetto editoriale "decimale", analogamente a quanto può avvenire per un effetto di chiusa, non si limita nei Carmina ad un solo componimento, ma si distribuisce su di una microsequenza ${ }^{64}$. Anche una possibile traccia editoriale del grande modello rappresentato dall'edizione alessandrina di Alceo sembra mirare al medesimo effetto. Infatti, se nell'edizione di Alceo le saffiche dell'inno ad Hermes, su cui è modellato il carme 1, 10, erano seguite dagli asclepiadei maggiori dell'inno alle Ninfe (fr. $343 \mathrm{~V}$.), il medesimo metro ricompare nel carme 1, 11 (sue uniche altre occorrenze oraziane sono 1, 18 e 4, 10): la micro-sequenza "saffiche-asclepiadei maggiori” è passata dall'edizione di Alceo all'edizione di Orazio, sebbene in assenza, in questo caso, di definiti riscontri tematici tra il carme 1, 11 e l'inno alle Ninfe ${ }^{65}$.

51 A Leuconoe il poeta consiglia di non "tentare" i numeri astrologici $(1,11,2-3$...nec Babylonios/temptaris numeros). Ma Orazio stesso ha "appena" contato, e disposto numericamente, i primi dieci carmi della sua raccolta: l'ansia esistenziale della "fine", ultimo approdo deciso dagli dèi (1-2 ...quem mihi, quem tibi/finem di dederint), si affaccia nel liber quando ne viene superato il primo netto confine, ancora non dissolta la figura ambivalente, "supera" ed infera, di Hermes psicopompo su cui il carme 1, 10 si è chiuso. (Non senza ironia, l'esorcismo della morte si rispecchia in Orazio tra le forme editoriali ed i temi poetici) ${ }^{66}$.

Dunque, nel disporre la sequenza inaugurale della sua raccolta lirica, se Orazio ha reso riconoscibile il limite del dieci, pure questo limite ha voluto sfumare. Per un meccanismo che non sorprende in Orazio, l'individuazione di una forma deve essere dissimulata ${ }^{67}$ : è "attorno" al confine del dieci che si concentrano, ma non si 
immobilizzano, i segnali metrico-tematici editorialmente rilevanti - il metro saffico; le figure divine e il connesso registro innico. Si tratterà ora di vedere se e come questa prima esperienza, che Orazio ha offerto al suo lettore, venga tenuta presente nella prosecuzione dei Carmina, se essa possa contribuire a creare delle costanti, e quindi una leggibilità nelle successive sequenze ${ }^{68}$.

\subsubsection{Altri due confini del dieci: 1, 20-21; 1, 30-31} quelle del carme 1, 12, il lettore che prosegua nello "svolgere" il libro, più non ne incontra fino al compiersi della seconda decina, nel carme 1, 20: tre strofe, in cui Orazio evoca all'amico Mecenate, attraverso gli emblemi del vino e del simposio, i valori "moderati" della propria poesia (vv. 1-2 Vile potabis modicis Sabinum/cantharis eqs.) ${ }^{69}$. Che anche in questo caso il metro saffico segni, nel dieci, il raggiungimento di un limite, sembra confermarlo l'immediata prosecuzione del liber: il carme 1, 21 è un vero e proprio inno, a Diana e ad Apollo, quindi opportunamente collocato, con funzione "inaugurale", ad aprire una nuova sequenza - Dianam tenerae dicite virgines,/intonsum, pueri, dicite Cynthium (vv. 1-2). Soltanto, dunque, all'inizio della sua terza decina di carmi (21-30), Orazio ha voluto collocare quella forma innica che gli era parso "prematuro", forse ironicamente "eccessivo", collocare nel luogo più naturale ed esposto, l'incipit dell'intera raccolta.

Eppure, anche qui, Orazio sembra aver voluto introdurre un correttivo al proprio discorso divino: l'immediatamente successivo carme 1,22 ci restituisce l'immagine di un poeta d'amore che, integer scelerisque purus, non ha ragione di temere gli eventi, che si tratti dell'enorme lupo, ovvero di viaggi su terribili mari: ...sive per Syrtis iter aestuosas/sive facturus per inhospitalem/Caucasum eqs. (5-7) ${ }^{70}$. Il riferimento alla dimensione divina diviene esplicita, ancora una volta, attraverso la figura meteorologica del padre degli dèi: ...quod latus mundi nebulae malusque/Iuppiter urget (19-20). Il tema divino, e la forma innografica della preghiera, non sembra ancora aver raggiunto una disposizione ideologicamente stabile, nel liber di Orazio. Il poeta, infatti, se non è macchiato dallo scelus, sembra dovere soprattutto al suo canto per Lalage ogni sua immunità.

Il lettore che prosegua nella terza decina incontrerà soltanto un nuovo componimento in saffiche, prima di raggiungerne la conclusione: il carme 1, 25 (si noti: a concludere la prima metà della sequenza decimale). Quindi, nel carme 1,30 , ancora una volta Orazio sceglie la strofa saffica per segnare il confine del dieci, e, in questo caso, sperimentando una nuova intersezione con il tema divino, che ora si fa esplicita preghiera: $O$ Venus, regina Cnidi Paphique,/sperne dilectam Cypron eqs. $(1,30,1-2)$. La funzione editoriale di "snodo" sembra esser tanto più rimarcata dalla estrema brevità: due sole strofe, per un totale di otto versi - una estensione, minima nel libro I, che accomuna il carme 1, 30 alla successiva, ed "ultima", conclusione, il congedo di 1, 38 (anch'esso in saffiche) ${ }^{71}$. Non è necessario ipotizzare che Orazio abbia composto il carme 1, 30 appositamente per collocarlo a suggello della sequenza 21-30 (d'altra parte: la creatività poetica dovrebbe forse sentirsi umiliata da uno stimolo editoriale, dal desiderio di completare un complesso disegno compositivo?). Ma senza dubbio, posto a completamento dell'ultima, compiuta, sequenza decimale del libro I, il carme 1, 30 va a disporsi all'interno di una articolata rete di significati: e il suo adonio finale, Mercuriusque, con cui la sequenza 21-30 (e la più ampia sequenza 1-30) si conclude, si richiama all'inizio 
del primo "vero" inno di Orazio, il carme 1, 10, che appunto nel nome del dio si era aperto - Mercuri, facunde nepos Atlantis ${ }^{72}$.

Il successivo carme 1, 31 riporta ancora una volta il lettore al tema della divinità: ma ora il poeta personalizza, riportando a se stesso la questione della preghiera - Quid dedicatum poscit Apollinem/vates? Finalmente, ormai giunto nella regione estrema del libro I, il lettore si trova di fronte un poeta lirico che ha il coraggio di rivolgersi ad Apollo. In precendenza, Orazio aveva voluto confrontarsi direttamente soltanto con l'inno ad Hermes dell'auctor Alceo. Adesso, nell'iniziare l'ultima sezione del libro (una "decina mancata"), Orazio si volge al dio con cui si apriva l'edizione di Alceo, e utilizzando lo stesso metro del modello: come nel fr. 307 V., la strofe alcaica. Dunque ma quanto tardivamente! - un inizio da emulo di Alceo.

Ancora, nel successivo carme 1, 32, Orazio torna ad utilizzare la strofe saffica: riesce confermata, con la terza iterazione dopo le coppie 1, 10/12 e 1, 20/22, la "cornice" in strofe saffiche a cavallo del confine decimale. In questo caso, inoltre, la sequenza alcaiche-saffiche, tra 1, 31 e 1, 32, potrebbe lasciar intravedere, almeno per un istante, il richiamo alla sequenza iniziale di Alceo: ma il carme 1, 32 evita (forse appositamente?) di nominare Hermes-Mercurio, sebbene esso tratti un oggetto musicale direttamente collegato al dio, la lira (si rammenti 1, 10, 6) - ...age dic Latinum,/ barbite, carmen (3-4) $)^{73}$. Ma l'evasività è compensata da un rinvio esplicito al modello: barbite [...] Lesbio primum modulate civi,/qui ferox bello, tamen inter arma/sive iactatam religarat udo/litore navim,/Liberum et Musas Veneremque et illi/semper haerentem puerum canebat eqs. (5-10). L"altro" Alceo, certo, erotico-simposiale, non quello stasiotico: ma appunto a Venere un breve "inno" Orazio ha appena rivolto nel carme 1, 3074.

\subsubsection{La sequenza finale del libro I}

Come abbiamo visto, riguardo agli dèi e alla natura divina Orazio ha scelto di esprimersi in luoghi editorialmente esposti del libro, cioè in corrispondenza del "quasi inizio", il carme 1, 2, e, quindi, nei successivi confini del dieci $(1,10$ e 1, 12; 1, 21; 1,30 e 1, 31). A ridosso dell'apollineo carme 1, 21, il carme 1,22 sembrava essersi acquietato in una visione leggera e disimpegnata, in cui a proteggere il poeta bastava, accanto all' “integrità", il pensiero dell'amata Lalage. Ancora nella sequenza 1, 30-31-32 le figure divine sono avvolte di una luce lieve e rassicurante: Venere, le Muse e Libero, un Apollo benigno cui il poeta si contenta di chiedere una vecchiaia "non turpe" e "non priva della cetra" (1, 31, 19-20). Se vengono evocate le dimensioni ostili e perigliose del mare e delle tempeste, e con esse la fortuna dispensatrice di beni, è soltanto, ancora nel carme 1,31 , con un moto di distacco, giacché la personale soluzione del poeta è nella riduzione dei bisogni, nel saper frui paratis (vv. 9-19). Sulla stessa linea, di sereno distacco, si pone il tema erotico del carme 1, 33, rivolto all'amico Albio (Tibullo, verosimilmente).

Ma non si chiude così il percorso divino di Orazio nel libro I. La figura del Padre divino signore del tuono, che, minaccioso, aveva avuto tanta rilevanza nella sequenza iniziale del libro, torna improvvisamente ad affacciarsi nel carme 1, 34, 1-12:

Parcus deorum et infrequens

insanientis dum sapientiae consultus erro, nunc retrorsum vela dare atque iterare cursus 


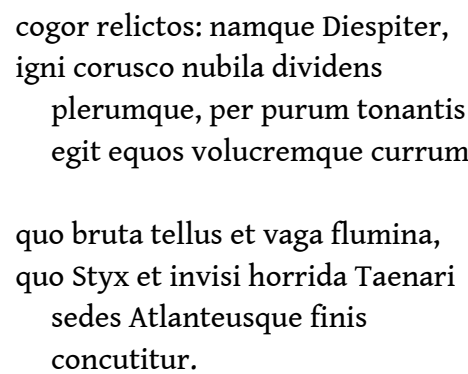

60 Al rispetto degli dèi Orazio viene ricondotto dalla folgore di Giove, emblema del sommo potere, che giunge, inspiegabilmente, a spezzare un limpido cielo (per purum): l'immagine nautica (nunc retrorsum vela dare), ancora una volta, colloca nella dimensione marina, come metafora dell'evento, l'esperienza individuale dell'uomo e del poeta. La "ripetizione di una rotta già seguita"75, oltre che attuata nel percorso morale di Orazio, è editorialmente evidente al lettore, che, dopo i leggeri carmi divini "appena" letti, vede sotto i propri occhi riemergere il Giove meteorologico su cui si era aperto il carme 1, 2 (e che aveva resistito "ancora" fino alla chiusa del carme 1, 12). Effettivamente, il poeta Orazio sta tornando sui propri passi, cioè alla sequenza iniziale del liber. E un tale rovesciamento potrebbe essere non altro che una tra le conseguenze (editoriali) del potere di Giove: valet ima summis/mutare (12-13). Ancora una volta la raccolta lirica si svela esser predisposta come riflesso, o duplicazione, dell'esperienza del poeta.

61 A rimarcare la rilevanza di questo luogo del liber, qualificandolo come decisivo punto di snodo, si aggiunge l'uso di una forma editoriale che, nel libro I e in generale nei Carmina, Orazio impiega solo sporadicamente e, spesso, in previsione di precisi effetti: la microsequenza omometrica ${ }^{76}$. Proseguendo dunque in alcaiche, Orazio passa a rivolgersi alla Fortuna, la Dea di Anzio su cui, nei modi allocutivi dell'inno, si apre il carme 1, 35. A rinsaldare il nesso non è soltanto l'identità metrica, ma l'esplicita anticipazione del carme 1, 34, vv. 14-16, in cui ad esser nominata è appunto la fortuna, come forza capace di ribaltare il destino degli uomini. E lo sguardo retrospettivo del carme 1, 34 al lettore sembra di ritrovarlo ancora nel carme 1, 35, che lo riconduce ai grandi temi della res Romana, alle alternanze nei domini sui popoli, a Cesare, pronto ad imbarcarsi verso i più lontani Britanni (anche qui, la dimensione remota del mare completa la costruzione teologica, e ideologica, oraziana). Se il nesso omometrico mette in risalto la sequenza 1, 34-1, 35, la collocazione all'interno del liber qualifica il carme 1, 35 come "risposta" alla problematica divina già drammaticamente impostata da Orazio nel carme 1, 2: dall'un capo all'altro del libro i temi si corrispondono, sembrano dialogare.

Come settimo multiplo di cinque, per la rilevanza del suo tema divino, per il nesso a cornice con l'inizio, il carme 1, 35 avrebbe potuto rappresentare un'opportuna conclusione del libro I. Ma Orazio non ha ancora esaurito la sua materia, e si spinge ad aggiungere ancora tre carmi. Il carme 1, 36 riprende il discorso divino, riportandolo ad una dimensione privata e rassicurante. In contrasto con le accese domande su cui si chiudeva il carme 1, 35, prospettando desolanti scenari di un'empia gioventù (unde manum iuventus/metu deorum continuit? quibus/pepercit aris? eqs. [36-38]), il carme 1, 36 si apre invece sul gioioso rito domestico per il ritorno di un amico da terre lontane, giunto sospes a Roma - dunque, esempio di come la fortuna possa anche proteggere gli uomini. Con il carme 1, 37, infine, la salvezza si estende all'intero popolo Romano, nell'esultanza per la sconfitta di Cleopatra. Dunque, Orazio, che aveva suscitato, 
all'altro capo del liber, così forti ansie sul destino di Roma, minacciata da una divinità tanto punitiva ${ }^{77}$, ora decide di scioglierle, prima attraverso il lieto destino di chi negli dèi ha trovato protezione ( $1,36,3$ custodes Numidae deos), poi attraverso l'ebbrezza liberatoria del dopo Azio. E tra i due componimenti un filo rosso è segnato esattamente dal tema dell' "eccesso" saliare, con una ripresa a pochi versi di distanza (nove) che difficilmente può passare inosservata: 1, 36, 12 neu morem in Salium sit requies pedum $\approx 1$, 37, 1-4 nunc pede libero/pulsanda tellus, nunc Saliaribus/ornare pulvinar deorum/tempus erat dapibus ${ }^{78}$.

Nella zona marginale attraverso cui il libro I supera i 35 carmi, senza giungere a 40 , Orazio ha trovato il modo di esprimere concetti ideologici (e poetici) fondamentali della sua costruzione lirica. Finalmente giunge, variando in toni soffusi il tema del banchetto, il carme 1, 38, Persicos odi, puer, apparatus ${ }^{79}$. In esso il libro I trova la sua chiusa editorialmente efficace: la simbologia poetologica degli oggetti simposiali; la brevità minima (due strofe, come nel carme 1, 30); l'uso della strofe saffica, a sigillo, e autenticazione, di quest'ultima, incompleta, decina, e dell'intero liber $^{80}$. Ancora il poeta lirico Orazio non si sente pronto per forme editorialmente "perfette": il numero nondecimale di 38 , se anche può aver avuto concause occasionali ${ }^{81}$, è divenuto ragione espressiva di questo incompiuto ruolo di lyricus. Per un tipico modo oraziano, spetterà al successivo libro "sfrondare", "selezionare", "razionalizzare".

\subsection{Metamorfosi e fuga dal libro II}

Nella sua equilibratissima disposizione il libro II giunge come una conferma, per il lettore che abbia sviluppato attraverso il libro I una sensibilità ai criteri strutturali adottati da Orazio. Infatti, nei venti carmi del libro II (multiplo decimale finalmente "perfetto") è riconoscibile una sequenza iniziale, che si spinge fino alla metà esatta del libro, identificata dall'alternanza sistematica dei metri: il carme 2, 1 è in alcaiche, mentre in saffiche è il carme 2, 2, e così via nei carmi successivi, fino al carme 2, 10 compreso. A compattare ulteriormente la sequenza 2, 1-10 è l'aspetto tematico, dal momento che, se si escludono, come "cornice", la 2, 1 e la 2, 10, vi si distingue chiaramente una serie di coppie unite dall'analogia di argomento: 2-3 (la necessità della saggezza di fronte alle alternanze della sorte); 4-5 (l'eros); 6-7 (l'amicizia: Settimio e Pompeo); 8-9 (ancora l'eros) ${ }^{82}$. Dunque, Orazio ha rispettato, anche nella seconda "unità" della raccolta lirica, il confine del dieci, che in questo caso segna una bipartizione del libro in due metà. Come già abbiamo più volte osservato, ad individuare Epodi 1-10 era stata la omometria; in Carmina 1 Orazio si era affidato invece alla eterometria, interrotta dall'iterazione della saffica nel carme 1, 10: ora è l'alternanza dei metri a individuare i carmi 2, 1-10. La dialettica metro-tema è resa tanto più evidente dalla contrastiva forza di attrazione tematica che, opponendosi all'alternanza metrica, distribuisce per coppie i singoli carmi.

Del libro I sembra ancora percepibile la traccia ideologica. Al momento di riprendere il proprio discorso lirico, infatti, Orazio richiama ancora una volta il lettore sull'urgenza di un contesto storico, che ancora non è pacificato: il carme 2, 1, anticipando, con le sue dieci strofe (per un totale di 40 versi), la perfetta struttura decimale del libro II, non si rivolge infatti a divinità o a eroi divinizzati. Ma tutto l'articolato discorso teologico che, lumeggiato dai luoghi esposti "attorno" al confine del dieci, attraversava il libro I, e ne rappresentava una cruciale acquisizione, sembra ora essere accantonato, perché il 
poeta, rivolgendosi (in alcaiche!) all'importante destinatario Asinio Pollione, si concentra sulla sanguinosa stagione delle guerre civili, di cui ancora deve essere scritta la storia. Se l'idea è quella della $\sigma \tau o ́$ oı, , il termine scelto da Orazio, in incipit, è quello di motus...civicus $(2,1,1)$ : con esso il lettore ritrova un attacco dinamico, che lo riporta all' Ibis con cui si aprivano i battaglieri, e politicizzati, Epodi ${ }^{83}$. Ad essere nominata, oltre alla convenzionale Musa (vv. 9; 37) è soltanto, fuggevolmente, l'anti-romana Giunone, assieme ad altri non specificati, ipotetici, dèi "amici" all'Africa (25-28): con l'abituale mossa ricusatoria, è l'antro di Venere ("Dioneo") che Orazio in chiusa rivendica a sé (39-40).

Nella prosecuzione del libro il lettore non incontrerà quelle forme inniche, preghiere o invocazioni alla divinità, che cadenzavano il passo del libro I. Ma pure non mancano di apparirvi gli dèi, in special modo nel momento in cui il destino del singolo si confronta con i perigliosi eventi della guerra e della lotta civile: nel carme 2, 7 - dal quale, crediamo, si diparte un nesso che risale al carme $1,14^{84}$-, accanto al salvifico Mercurio cui Orazio dovette la propria incolumità, si affaccia il termine sommo dell'autorità divina, lo stesso Giove (17 ergo obligatam redde Iovi dapem eqs.). Ma è sulla Storia che si appunta l'attenzione di Orazio: e non senza tutta l'evidenza inattesa di un'intrusione.

Ormai prossimo a concludere la sequenza decimale, nel carme 2, 9, Orazio improvvisamente devia dal tema erotico, comune al precedente carme 2,8 , e così si rivolge a Valgio Rufo addolorato per la scomparsa dell'amato Miste: desine mollium/ tandem querellarum et potius nova/cantemus Augusti tropaea/Caesaris eqs. (17-20). Nella movenza colloquiale del quasi risentito tandem, oltre all'intento consolatorio, si percepisce l'urgenza del discorso politico (panegiristico). La necessità di una misura nel dolore umano, che corrisponda alle leggi di alternanza che regolano il corso naturale, è qui una certezza, come nel carme 1,2 era una speranza - quella dell'argine risolutivo alla devastazione voluta da Giove (vv. 1-2 Iam satis terris nivis atque dirae/grandinis eqs.): ancora, la meteorologia come emblema degli eventi che decidono il destino umano, che si tratti del singolo o di intere comunità, che si tratti dell'amore o delle guerre.

68 A questo punto, dopo le alcaiche a Valgio Rufo, il libro II, proseguendo nel suo ritmo binario, passa con il decimo carme alla strofe saffica: si trova, così, ad essere ancora una volta rispettata la "legge" del limite decimale (che, fino a questo punto del corpus lirico non ha avuto deroghe). Sull'immagine della navigazione, che prudentemente va mantenuta tra l'alto mare e la riva, il carme 2, 10, rivolgendosi all'amico Licinio, si apre: ancora le tempeste marine rappresentano la dimensione del pericolo, da evitarsi Rectius vives, Licini, neque altum/semper urgendo neque, dum procellas/cautus horrescis, nimium premendo/litus iniquom (1-4). Nel "sempre", per Licinio come per il Valgio del precedente carme, Orazio riconosce una perversione propria dell'uomo. Proprio perché si possa rispondere alle contrastanti sollecitazioni della natura e della sorte, è necessario tenere una rotta mediana, che permetta rapidi quanto lucidi adeguamenti.

In questo tema ricorrente del libro II, che il lettore ha già incontrato più volte (si ricordi ad es. il carme 2, 3; e, in chiave erotica, 2, 5, 9-15), trova una profonda motivazione quell'alternanza che, anche a livello strutturale, ne è il tratto identificante: il libro II vive, nella sua sequenza iniziale, di un ritmo continuo, che il poeta riconosce nella natura e nel destino, ed al tempo stesso esprime attraverso l'avvicendarsi dei suoi due principali metri. Ed esattamente nel carme 2,10, che con le sue sei strofe saffiche si mantiene in studiato equilibrio a chiudere la prima metà del libro, trova espressione una tra le più memorabili formule oraziane della misura: auream quisquis mediocritatem/ 
diligit, tutus caret obsoleti/sordibus tecti, caret invidenda/sobrius aula (5-8). Ancora una volta, la disposizione nel liber si connette per via diretta all'espressione lirica di Orazio. Il poeta stesso, nel gestire il proprio percorso nei Carmina, dovrà saper usare di misura $\mathrm{e}$ moderazione: i turgida vela su cui si chiude il carme 2, 10, e con esso la prima parte del libro II, sembrano esprimere il moto di una poesia che ormai proceda spedita ${ }^{85}$. Ma potrà essere che Orazio, come nel carme 1,34 , debba esser pronto ad invertire la rotta della sua navicella (3-4 retrorsum/dare vela), o a raffrenarla - sapienter idem/contrahes vento nimium secundo/turgida vela $(2,10,22-24)$.

Passando l'asse di simmetria del libro II subito dopo il carme 2, 10, spetta alle alcaiche del carme 2, 11 aprirne la seconda metà. E anche da "questa" parte del libro si ritrova il motivo del "non-sempre": 2, 11, 9-12 non semper idem floribus est honor/vernis neque uno luna rubens nitet/voltu. Non convince l'ipotesi di chi ha voluto includere il carme 2, 11 nella prima parte del libro: esso non è seguito, infatti, da un carme in saffiche, sebbene, di per sé, esso prosegua l'alternanza rispetto alle saffiche del carme $2,10^{86}$. Sembra, in realtà, che Orazio qui abbia messo a contrasto due forme di "confine editoriale": quella, decimale-saffica, del carme 2, 10; e quella, giocata sul destinatario, del carme 2, 12, che si rivolge a Mecenate (come la sat. 1, 6, che apriva la seconda parte di Serm. ${ }^{17}$ ). Un margine di libertà Orazio se l'è riservato, "sfalsando" due tra le sue più vistose funzioni editoriali: l'allocuzione all'illustre amico è infatti "ritardata" di una posizione (all'illustre Licinio Murena è dedicato invece il carme 2, 10).

71 Immediatamente, la seconda parte del libro II riporta il lettore a quello che è uno dei suoi temi fondamentali, già iniziale, la Storia. In realtà, in un primissimo momento, è con un moto di distacco simposiale che il poeta guarda ai pericoli di lontani e ostili popoli (e, in questo caso, il mare diviene baluardo protettivo): Quid bellicosus Cantaber et Scythes,/Hirpine Quincti, cogitet Hadria/divisus obiecto, remittas/quaerere (2, 11, 1-4; cf. 17 potamus). Anche nel successivo carme 2, 12, la retorica ricusatoria viene temperata dall'azione storiografica di Mecenate, che, in un eventuale futuro, potrà narrare le imprese di Cesare, i suoi trionfi - e il termine questa volta è esplicito, "tecnico": pedestribus/...historiis (9-10). E così, ancora, nel carme che chiude la terza cinquina, nel quale, per il metro e il tema morale, trovano un'anticipazione le Odi romane (qui la dimensione storica si attua nella necessità di una riforma dei costumi): non ita Romuli/ praescriptum et intonsi Catonis/auspiciis veterumque norma $(2,15,10-12)^{88}$.

$72 \mathrm{Ma}$, al momento di chiudere il suo secondo libro, Orazio ancora decide per un mutamento, giocato, anche questa volta, sul tema divino. Nel pre-finale del libro I, con la sequenza 1, 34-35-36, il lettore era stato messo di fronte ad un "ripensamento" teologico del poeta, innescato dal tuono di Giove. Adesso, Orazio inserisce nel carme che precede la chiusa il resoconto di un'esperienza mistico-dionisiaca: Bacchum in remotis carmina rupibus/vidi docentem - credite posteri - $(2,19,1-2)$. La magnificazione del dio è tale, che Orazio ne rammenta il ruolo avuto come difensore di quello stesso Giove che rappresenta (e ha rappresentato nel libro I) la somma autorità: tu, cum parentis regna per arduum/cohors Gigantum scanderet impia,/Rhoetum retorsisti leonis/unguibus horribilique mala (21-24). Il simbolo stesso dell'incontrollabilità, in Orazio, è sottoposto alla forza del dio: tu flectis amnes, tu mare barbarum,/tu separatis uvidus in iugis/nodo coerces viperino/Bistonidum sine fraude crinis (17-20) - ovvero, la prerogativa di intervenire sui liquidi qualifica Bacco anche come dominatore dei fiumi, del mare, e quindi come entità meteorologica (e l'epiteto di "Libero" finisce per realizzarsi nel suo opposto: nodo coerces viperino). Nell'ultima strofa, infine, la tipologia della "chiusa 
oscura" ${ }^{89}$ viene evocata a contrasto: Bacco, con il suo solo apparire, avrebbe domato il cane infernale Cerbero, e, con esso, la morte, uno tra i temi dominanti, e ossessivi, del lirico Orazio. Per un effetto strettamente editoriale, la prossimità del finale di libro riporta il poeta, anche in un libro relativamente "laico" come il II, alla divinità. E, con la figura di Bacco, il pre-finale del libro II corrisponde al dionisiaco pre-finale del libro I, il carme 1, 37 Nunc est bibendum.

$\mathrm{Ma}$, con un nuovo moto, il vero e proprio finale del libro si sottrae alle aspettative del lettore. Il libro I, sebbene nel numero "incompleto" di 38, aveva fatto pausa su di un luminoso quadro di semplice eleganza simposiale, in cui si specchiava la personalità e la poesia di Orazio. Invece, nel chiudersi, il libro II prospetta per il poeta una "inusitata" trasformazione, che lo sottrarrà ai limiti della vita umana, che lo libererà dalla morte: Non usitata nec tenui ferar/penna biformis per liquidum aethera/vates eqs. (1-3). In qualche misura, il carme 2, 20 è "preparato", come da tempo non si è mancato di osservare, dal carme 2, 19: è innegabile che la trasformazione del poeta ripeta il percorso liberatorio indotto da Bacco, e che la strofa finale, con il rifiuto di un lutto necessariamente "inutile", rimandi all'immagine di Cerbero ammansito dal dio (anch'essa in chiusa) ${ }^{90}$. Ma questo non ha impedito al carme 2, 20, secondo le parole dello stesso Orazio (si ricordi l'epiteto inusitata), di sorprendere generazioni di lettori, con la sua "inconsueta" invenzione.

È che nella analitica descrizione di come il suo corpo si muta, per prendere le sembianze di uccello (vv. 9-12), Orazio esprime, non senza una percepibile voluttà, quell'istanza alla fuga, al cambiamento, che è il correlato dialettico della ricerca di protezione: accanto ad una studiatissima architettura di forme, ad un controllo razionale che si esplica nella retorica della metriótes, dell'angulus ${ }^{91}$, c'è nell'opera oraziana una spinta al superamento, alla liberazione (alla pluralità di forme, anche in contrasto tra loro: biformis...vates). Ecco perché, mutato in un uccello che gli permette di superare Icaro (e l'arte di Dedalo), Orazio può spingersi ad immaginare di superare il confine più temibile, quello di mari remoti: ...visam gementis litora Bosphori/Syrtisque Gaetulas canorus/ales Hyperboreosque campos (14-16). E lo "strappo" del carme 2, 20, il suo nervoso divincolarsi, si fa evidente anche rispetto alle consuetudini editoriali che, fino ad ora, Orazio ha sistematicamente rispettato: nonostante esso occupi la compiuta posizione decimale, a conclusione di un libro perfettamente equilibrato nelle sue due metà di dieci (e a conclusione dei primi due libri dei Carmina), il carme 2, 20 abbandona per la prima volta la strofe saffica. Orazio si è sottratto, con la metamorfosi, anche alle forme già stabilite del proprio liber: e, come 1, 37-1, 38 anticipavano l'alternanza alcaica-saffica di 2, 1-10, così la coppia omometrica 2, 19-20 deve preludere ormai alle "successive" Odi romane.

\subsection{II perfetto ciclo delle Odi romane}

Il libro III si apre con una sequenza che esige una lettura continuata: il dispositivo omometrico, già occasionalmente sperimentato da Orazio, viene sfruttato intensivamente. Senza dubbio, a questa eccezionalità editoriale vuole alludere la dichiarazione di assoluta novità con cui si apre il primo carme: carmina non prius/audita (3, 1, 2-3; cf. 2, 20, 1-2 cit.). Dopo tante ricusazioni, il poeta dei Carmina, che le alcaiche dei carmi 2, 19-20 ci hanno consegnato nel suo ruolo di immortale vate bacchico,è ora pronto ad arditezze ${ }^{92}$. 
76 Proprio la omometria, che è ragione di confronto e sinossi per una sequenza di singoli componimenti da considerare come "ciclo", è parsa invece il maggior sostegno all'ipotesi di chi ha voluto considerare le Odi romane come un unico componimento, di eccezionale lunghezza ${ }^{93}$. Ma, a dimostrare che Orazio considerava i carmi 3, 1-6 come singoli componimenti distinti, è l'uso di quei dispositivi editoriali che, altrimenti, mal si comprenderebbero: ad esempio la presenza di un secondo proemio, "al mezzo"94, ad aprire la seconda metà del ciclo. L'esperienza del lettore, che può “ormai” essere presupposta all'inizio del libro III, non dovrebbe lasciargli margini di dubbio: il libro I si apriva con una sinfonia di temi e metri diversi; il libro II con una sistematica alternanza di metri, per temi raggruppati due a due; il libro III intensifica l'uso, fino ad ora occasionale, dell'omometria per un tema, ed un impegno poetico-morale, "non prima ascoltato". Ad ulteriore conferma, soltanto nel caso che le Odi romane vengano contate come sei distinti carmi, il carme 3, 16, indirizzato a Mecenate, si trova ad occupare la posizione d'onore al centro del libro, aprendone la seconda metà (al pari di sat. 1,6).

Una tale competenza editoriale rappresenta soltanto un aspetto delle molteplici memorie, specificamente lirico-oraziane, che le Odi romane sollecitano nel lettore: infatti, tornano in esse $\mathrm{i}$ temi e le forme ideologiche che hanno caratterizzato i due precedenti libri. Dal nostro punto di vista, è facile osservare come già nel carme 3, 1 si riaffaccino la divinità e la tempesta: dopo le Muse, consuete personificazioni della poesia, il regno di Giove (6 imperium...Iovis); e, come emblema dell'evento incontrollabile, al cui pericolo si espone chi è insoddisfatto della propria sorte, ancora, il mare e la tempesta: desiderantem quod satis est neque/tumultuosum sollicitat mare,/nec saevus Arcturi cadentis/impetus aut orientis Haedi, eqs. (25-28) ${ }^{95}$. Anche il carme 3, 3 sintetizza e completa, inserendoli all'interno del grande quadro ideologico e religioso, $\mathrm{i}$ temi teologici e politici che abbiamo seguito nel loro intrecciarsi all'interno del libro I. Nell'imperturbabilità dell'uomo giusto, inattaccabile dalle passioni politiche dei concittadini e dalla tirannia, come dai venti che tumultuano sul mare o dalle folgori di Giove $(3,3,1-8)$, ritorna, ormai fattosi ovvio, il nesso stasiotico-meteorologico, che Orazio aveva allegorizzato nel carme 1,14 .

\subsubsection{Un "ultimo" confine del dieci? $(3,20-21)$}

Superata la sequenza iniziale delle Odi romane, il libro III si dispiega in tutta la complessa articolazione dei suoi temi: dal punto di vista strutturale, dopo il "liberatorio" carme 2, 20, esso non ha più ragione di rispettare le consuetudini che erano valse, come abbiamo visto senza deroghe, nel libro I e nella prima parte del libro II. Il lettore non deve sorprendersi, allora, che il carme 3, 10 confermi, nel confine decimale, l'abbandono della strofe saffica: in metro asclepiadeo, Orazio lamenta la ianua serrata, che lo esclude dall'incontro con la crudele Lyce. Sembra essere anzi il poeta stesso a rimarcare la differenza, rievocando il confine della sua "prima" sequenza decimale, quella del libro I: infatti, ad iniziare la successiva decina è una invocazione a Mercurio in saffiche, che è una chiara variazione, sul tema erotico, di $1,10^{96}$ (se si preferisce, si può anche dire che, ritardandolo di una posizione rispetto ad 1, 10, Orazio ha fatto sì che 3, 11 si trovi, come 1, 21 e 1, 31, a fungere da "inno" inaugurale di una nuova decina).

79 Ma, prima di giungere all'ultimo confine decimale, quello del carme 3, 30 (che, per il metro, si ricollega a 1,1 ), Orazio sembra essersi ancora un'ultima volta rammentato delle "precedenti" consuetudini strutturali. Infatti, in strofe saffiche è il carme 3, 20, 
mentre il successivo carme 3, 21 è un'allocuzione all'anfora, in alcaiche, che ha la forma di un vero e proprio inno. Dunque, la sequenza 3, 20-21 sembra corrispondere perfettamente ad una sequenza come 1, 20-21: ma qui, l'evocazione del confine decimale in saffiche (con l'annesso "inizio" innico in alcaiche), serve soltanto a far risaltare i modi, scherzosi, di una parodistica aretalogia religiosa - $O$ nata mecum consule Manlio ... pia testa ... descende ... (vv. 1-7; si noti, inoltre, il Du-Stil nei vv. 13; 17; 21) ${ }^{97}$.

\subsubsection{La sequenza finale della raccolta in tre libri}

Avviandosi a concludere il libro III, e quindi l'intera raccolta in tre libri, Orazio si trova a superare un ultimo, potenziale, confine multiplo di cinque, quello segnato dal carme 3 , 25. Come nel libro I, sembra che il poeta abbia rimarcato questo confine attraverso il tema divino: il carme, infatti, si apre con un"esplicita allocuzione - Quo me, Bacche, rapis tui/plenum? (1-2). Ritroviamo il poeta dionisiaco del carme 2, 19, che ora, però, si fa piuttosto analitico nel descrivere gli effetti del dio: quae nemora aut quos agor in specus/ velox mente nova? quibus/antris egregii Caesaris audiar/aeternum meditans decus/stellis inserere et consilio Iovis? (2-6). Il "rinnovarsi" della mente, che si fa rapida, non spinge Orazio soltanto verso "boschi" o "caverne": o meglio, ci potranno essere "antri" in cui egli si trovi a cantare i grandi temi dell'ideologia augustea - includere Cesare tra le stelle, e nel consiglio presieduto da Giove. Al momento di superare quest'ultima soglia, prima che il libro si concluda, sembra che Orazio "spieghi" ciò che altrimenti resterebbe affidato esclusivamente all'effetto editoriale, omometrico, tra libro II e libro III: il percorso poetico descritto nel carme 3,25 è già stato attuato nel passaggio dall'epifania di Bacco in 2, 19 al "volo" di 2, 20 e, quindi, alla sequenza delle augustee Odi romane.

81 Finalmente, con il carme 3, 28, il libro III avvia la propria sequenza finale, che si estende agli ultimi tre componimenti: a segnare l'avvicinarsi della conclusione collabora il tema simposiale, che ritroviamo nell'apertura del successivo carme 3, 2998. Come già nei tre componimenti finali del libro I, il convivio, allargandosi alla cornice situazionale in cui la poesia stessa di Orazio trovava la propria occasione performativa, si rivela essere particolarmente adatto alla chiusa (o alla "pre-chiusa", come in questo caso), quando naturalmente il liber tende a collocarsi nel suo ambiente, di lettori, amici, destinatari (si pensi alla conclusione "corale" del libro I delle Satire [1, 10, 81-91]). Come nei due carmi successivi, nel carme 3,28 , che pure trova la propria occasione nella festa di Nettuno, la forma esplicita dell'inno resta assente, o, comunque, la divinità non vi ha il ruolo di diretto destinatario. Ma pure il canto divino vi trova spazio, sebbene mediatamente, proiettato nel tempo imminente di una performance poetica alternata tra Orazio stesso e Lyde: nos cantabimus invicem/Neptunum et viridis Nereidum comas;/tu curva recines lyra/ Latonam et celeris spicula Cynthiae,/summo carmine, quae Cnidon/fulgentisque tenet Cycladas et Paphum/iunctis visit oloribus;/dicetur merita Nox quoque nenia (9-16). E, in questa prospettiva mediata, "miniaturizzata", Orazio reduplica la più ampia struttura editoriale del proprio discorso divino: summo carmine (13) - egli dice, proprio quando si sta avviando a concludere la propria raccolta lirica ${ }^{99}$.

Che la conclusione si stia avvicinando, chiudendosi a cerchio con l'inizio, lo fa presagire il ricomparire di Mecenate, nel carme 3, 29: il riferimento alla antica, regale, discendenza dell'illustre amico (Tyrrhena regum progenies [1]), e lo stesso argomento del carme, che si può definire filosofico-diatribico, rinviano il lettore al carme d'apertura, in cui Orazio aveva passato in rassegna i diversi ßíol: Maecenas atavis edite regibus ${ }^{10}$. 
Spetta al nesso tra il dio e la tempesta sugellare questo carme che si appresta così evidentemente ad essere l'“ultimo", a precedere il monumentale congedo: dapprima viene evocato il sommo Padre divino, le cui esternazioni meteorologiche, ormai, non potranno che fare da sfondo alla conquistata saggezza - cras vel atra/nube polum Pater occupato/vel sole puro: non tamen inritum,/quodcumque retro est, efficiet eqs. (43-46). Infine, nella chiusa vera e propria, sono gli specifici dèi della salvezza marina, i Dioscuri, a proteggere quella navicella nel mare in cui Orazio, metaforicamente, si identifica: non est meum, si mugiat Africis/malus procellis, ad miseras preces/decurrere et votis pacisci,/ne Cypriae Tyriaeque merces/addant avaro divitias mari;/tunc me biremis praesidio scaphae/ tutum per Aegaeos tumultus/aura feret geminusque Pollux (57-64). Il dio e la tempesta confermano, attraverso l'evidenza strutturale, la propria rilevanza tematica.

Finalmente, nel carme 3, 30 torna del carme 1,1 - dopo che ne sono stati evocati il destinatario e il linguaggio morale-diatribico - anche la forma metrica, mai altrove utilizzata nei primi tre libri dei Carmina: all'identità metrica Orazio affida la definizione degli estremi confini che delimitano la propria raccolta (come già dei confini interni, che suddividono le singole sequenze: il primo caso incontrato dal lettore è quello, che ormai conosciamo bene, della strofe saffica tra 1,1 e 1, 10). Ma, a ben vedere, è anche il tema centrale del carme 1, 1 a trovare qui una chiara ripresa: il poeta ha evidentemente raggiunto lo sperato traguardo, quello di essere incluso nel canone dei lirici - sume superbiam/quaesitam meritis et mihi Delphica/lauro cinge volens, Melpomene, comam $(14-16)^{101}$.

\subsection{Prospettive "postume", di inni e dèi, dal IV libro}

Lo sguardo retrospettivo, che era già nelle Odi romane, tanto più identifica l'ultimo libro dei Carmina, che Orazio aggiunge dopo aver lasciato passare un sensibile lasso di tempo, come il poeta stesso dichiara in apertura, seppure nella prospettiva, parzialmente disimpegnata, dell'eros (Intermissa, Venus, diu/rursus bella moves? [4, 1, 1-2]): i temi e le forme della precedente raccolta vi tornano variati, diversamente ricombinati. In questo suo "ritorno" (rursus) al canto, Orazio seleziona quelli che dovevano apparire a lui stesso temi cruciali della propria invenzione lirica: ne consegue che il libro IV riveste una preziosa funzione esegetica per il lettore dei primi tre libri quasi che il poeta lo affiancasse, guidandolo, nel lavoro interpretativo.

Come nell'insieme della precedente raccolta, il tema divino ha un ruolo vistoso nel IV libro, in cui compare direttamente connesso alla figura del princeps ${ }^{102}$ : a rappresentare l'incontrollabilità dell'evento è, ancora una volta, il mare con i suoi pericoli, che, nel carme 4,5 , viene osservato dalla prospettiva della madre ansiosa - come ansiosa è la patria per il ritorno del principe (9-16). Nel medesimo carme, immediatamente prima della conclusione, Augusto è assimilato, quale corrispettivo romano, ad Ercole e a Castore (ancora una volta i Dioscuri): te multa prece, te prosequitur mero/defuso pateris et Laribus tuum/miscet numen, uti Graecia Castoris/et magni memor Herculis (33-36). E, ancora, i due fratelli divini, nel loro ruolo "astrale" e "nautico", nuovamente in compagnia di Ercole, concludono il carme 4, 8: sic Iovis interest/optatis epulis impiger Hercules,/clarum Tyndaridae sidus ab infimis/quassas eripiunt aequoribus ratis,/ornatus viridi tempora pampino/Liber vota bonos ducit ad exitus (29-34) ${ }^{103}$. Dunque, da un'estremità all'altra della costruzione lirica oraziana, dal libro I al libro III e quindi al IV, tornano gli dèi (alcaici), protettori dei giovani guerrieri, tutela contro le tempeste, marine e stasiotiche. 

trovano una nuova sintesi, che presumibilmente Orazio riteneva ormai definitiva, nel carme 4, 15, con cui l'ultimo libro dei Carmina, sul multiplo di cinque, si conclude. Al pari del dio callimacheo degli Aitia, di cui già Orazio si era rammentato nell'ultimo componimento del suo primo liber pubblicato (sat. 1, 10, 32 vetuit me tali voce Quirinus), Apollo stesso interviene a raffrenare l'impegno del poeta: Phoebus volentem proelia me loqui/victas et urbis increpuit lyra,/ne parva Tyrrhenum per aequor/vela darem (1-4). Il dio augusteo, il dio di Azio e del Palatino, impedisce ad Orazio di proseguire per rotte perigliose, proprio quando egli aveva appena dato prova, con il carme 4, 14, di voler (e saper) lodare le virtù di Augusto: e questa volta il mare Tirreno, associandosi alla navicella dell'ingegno, assume un significato strettamente poetologico. Nelle Odi romane la sequenza omometrica in alcaiche rimarcava l'unità dell'impegno ideologico:

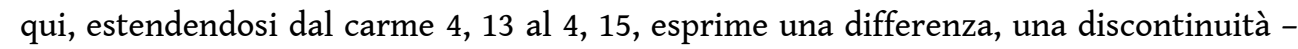
nel contrasto tra il tema civile di 4,14 , il tema erotico di 4,13 , ed infine la recusatio di 4 , 15.

Non di rado il tema ricusatorio viene attuato nel mezzo di un libro poetico: ma qui Orazio lo colloca in una posizione estrema, superata la quale il lettore non troverà più altri carmi - quasi dunque a cercare un effetto di "conclusione aperta", di ironico (o lievemente inquieto) "non-finito". Eppure, nelle sue due ultime strofe, è proprio su canti futuri che il carme 4, 15, e con esso il corpus dei Carmina, si conclude (vv. 25-32):

nosque et profestis lucibus et sacris

inter iocosi munera Liberi

cum prole matronisque nostris, rite deos prius apprecati,

virtute functos more patrum duces

Lydis remixto carmine tibiis

Troiamque et Anchisen et almae progeniem Veneris canemus.

Già verso la conclusione del libro III, il canto divino, l'elogio della divinità, aveva rappresentato la proiezione futura, e ottimisticamente indeterminata, della poesia di Orazio: nos cantabimus invicem/Neptunum eqs. $(3,28,10)$. Qui, in un tempo avvenire, nel quale la pace di Augusto si possa unire ad un idillico ritorno del mos maiorum, in una dimensione corale (nos) di mogli e figli a condividere gli scherzi di Bacco, il popolo di Roma canterà di condottieri, di Troia, di Anchise e della prole di Venere. Nel nos è evidentemente compreso anche quell'Orazio che mai volle stabilmente unirsi ad una donna, che, a quanto sappiamo, non ebbe figli, che, non senza un sottile piacere, ha "appena" assistito, nel carme 4, 13, all'invecchiare di Lyce, donna un tempo ammirata.

Quella stessa forma preliminare dell'inno, che Orazio nel proprio avvio lirico aveva differito, non mancherà a questi futuri simposi poetici: rite deos prius apprecati - dice il poeta che tanto aveva voluto indugiare, al momento di inserire nel liber il proprio compiuto "proemio". È vero che il carme 3,30 aveva già chiuso il cerchio, richiamandosi in modo inequivocabile, attraverso l'identità metrica, al carme 1,1 . Ma con l'allusione alla ritualità del proemio anche il carme 4, 15 sembra volersi rifare all'apertura dei Carmina - tracciando, si direbbe, un cerchio più ampio. Anche perché il carme 4,15, aprendosi in strofe alcaiche su Apollo, ripete l'inizio stesso di Alceo: l'inno,

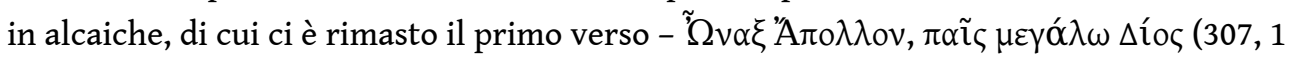
V.). Forse una conclusione opportuna, per un poeta che era ormai divenuto l'Alceo 
romano, ma che tanto aveva esitato, al suo "esordio", prima di invocare gli dèi di Alceo - discedo Alcaeus puncto illius (epist. 2, 2, 99).

\section{La struttura e il dio: controllo editoriale e perpetuo inizio}

Secondo quanto è stato osservato da L. Canfora, gli autori antichi, in special modo gli storici, che avessero intrapreso opere unitarie in più volumi, potevano premunirsi attraverso specifici accorgimenti editoriali contro il pericolo che i rotoli si scompaginassero: questo è il caso, ad esempio, di Diodoro Siculo, che usa incominciare un nuovo libro-rotolo con l'indicazione del numero d'ordine e riassumendo il contenuto del volume precedente ${ }^{104}$. Trattandosi di un ultimo libro, il nesso poteva essere stabilito con l'inizio dell'opera intera: così in esemplari erodotei noti a Dionigi di Alicarnasso, in cui il testo del libro IX terminava con le parole iniziali del libro I ${ }^{105}$.

Dunque, Orazio poteva aver in mente un preciso uso editoriale, nel predisporre una continuità tra l'inizio e la fine della propria raccolta in tre libri: ovvero, se si preferisce, anche ad un'esigenza di controllo (editoriale e autoriale) rispondeva la comunanza di metro tra il carme 1, 1 e il carme 3, 30 - da un poeta incerto sul proprio futuro di vates al monumentum aere perennius; da un poeta che non ha "ancora" la propria raccolta a un poeta che l'ha conclusa e deve tutelarla, chiudendola a cerchio ${ }^{106}$. Da questa prospettiva si fa meglio comprensibile nel suo preciso significato editoriale, come nesso "accorpante" che garantisca la continuità dall'uno all'altro libro (oltreché il passaggio dalla fine all'inizio), quel fenomeno che già abbiamo avuto occasione di osservare: gli ultimi due carmi di ogni libro anticipano la forma metrica della sequenza che apre il libro successivo (1, 37-38 alternano alcaica e saffica, anticipando 2, 1-10; 2, 19-20 sono entrambi in alcaiche, così da anticipare l'omometria alcaica di 3, 1-6).

La definizione di un limite (l'angulus) è un aspetto fondamentale dell'intuizione poetica oraziana, che vive dell'acuta dialettica tra moti emotivi e strutture formali rigide, "protettive": soltanto occasionalmente il poeta da queste protezioni, che con tanta paziente arte ha costruito, si divincola. In quei rari casi è la poesia, intesa come forza assoluta e trascinante, che permette ad Orazio di spezzare l'equilibrio tra l'ansia e l'effetto contrastivo del controllo razionale ${ }^{107}$. Il numero, nella sua rigida esattezza, forma perfetta di controllo razionale, è un mezzo privilegiato per ottenere quell'ordine rassicurante ${ }^{108}$. Con la sua statica monumentalità, il carme 3, 30 esprime appunto il compiersi di un edificio strutturato secondo un ordine fatto, anche, di forme numeriche. I tre libri dei Carmina vi acquistano l'evidenza di un robusto edificio, per significare la semi-immortalità del poeta (non omnis moriar). Ma che in Orazio la poesia si esplichi nell'impulso, metamorfico e liberatorio, di un superamento, il lettore lo sa dal precedente e complementare congedo, quello del libro II.

Una tale profonda dualità tra il controllo razionale (protettivo) e l'istante liberatorio si riflette inevitabilmente su quelle figure divine che occupano i ruoli autorevolmente, ed editorialmente, più esposti dei Carmina. Il dio esprime il controllo ed il limite, ed al tempo stesso sua è la prerogativa proemiale, quella cioè di avviare e perpetuare la poesia. C'è dunque una profonda coerenza, l'iterarsi di una precisa intuizione poetica, nel fatto che Orazio, giunto a quello che sarebbe rimasto il suo ultimo congedo lirico, concluda con il canto il libro IV. L'ultima parola dei Carmina è canemus, e l'ultima 
divinità che vi sia nominata Venere (almae/progeniem Veneris): per la sua capacità generativa, progenitrice di Enea e di Roma - alma come era stata nel grande inizio del poema sulla natura rerum $^{109}$.

\section{BIBLIOGRAFIA}

Argentieri 1998: L. Argentieri, Epigramma e libro. Morfologia delle raccolte epigrammatiche premeleagree, «Zeit. Pap. Ep.»121, 1998, pp. 1-20

Barchiesi 1997a: A. Barchiesi, voce "proemi e chiuse”, in Enc. Or., II, Roma 1997, pp. 727-732

- 1997b: A. Barchiesi, voce “sequenze”, in Enc. Or., II, Roma 1997, pp. 741-742

- 2000: A. Barchiesi, Rituals in Ink: Horace on the Greek Lyric Tradition, in M. Depew, D. Obbink (edd.), Matrices of Genre. Authors, Canons, and Society, Cambridge, Mass.-London 2000, pp. 167-182 - 2005: A. Barchiesi, The Search for the Perfect Book: A PS to the New Posidippus, in K. Gutzwiller (ed.), The New Posidippus. A Hellenistic Poetry Book, Oxford 2005, pp. 320-342

Bartels 1973: Ch. Bartels, Die neunte Epode des Horaz als sympotisches Gedicht, «Hermes»101, 1973, pp. 282-313

Belling 1903: H. Belling, Studien über die Liederbücher des Horatius, Berlin 1903

Bing (1988): P. Bing, The Well-Read Muse. Present and Past in Callimachus and the Hellenistic Poets, Göttingen 1988

Cairns 1995: F. Cairns, Horace's First Roman Ode (3.1), in Papers of the Leeds International Latin Seminar, 8, 1995, pp. 91-142

Canfora 1974: L. Canfora, Conservazione e perdita dei classici, Padova 1974

Cavallini 1979: E. Cavallini, Saffo e Alceo in Orazio, «Mus. Cr.» 13-14, 1978-1979, pp. 377-380

- 1996: E. Cavallini, voce “Alceo", in Enc. Or., I, Roma 1996, pp. 626-629

Cavarzere 1996: A. Cavarzere, Sul limitare. Il «motto» e la poesia di Orazio, Bologna 1996

Coffey 1976: M. Coffey, Roman Satire, London $1976\left(1989^{2}\right)$

Commager (1957): S. Commager, The Function of Wine in Horace's Odes, «Trans. Proceed. Amer. Philol. Ass.» 88, 1957, pp. 68-80

- (1962): S. Commager, The Odes of Horace, New Haven-London 1962

Cucchiarelli 1997: A. Cucchiarelli, “Allegoria retorica' e filologia alessandrina, «Stud. Ital. Filol. Class.» s. III, 15 , 1997, pp. $210-230$

- 2003: A. Cucchiarelli, rec. a "T. Woodman-D. Feeney (edd.), Traditions \& Contexts in the Poetry of Horace, Cambridge 2002”, «Journ. Rom. Stud.» 93, 2003, pp. 244-246

- 2004: A. Cucchiarelli, La nave e lo spettatore. Forme dell'allegoria da Alceo ad Orazio, «Stud. Ital. Filol. Class.» s. IV, 2, 2004, pp. 172-88 (prima parte) 
- 2005: A. Cucchiarelli, La nave e lo spettatore. Forme dell'allegoria da Alceo ad Orazio, «Stud. Ital.

Filol. Class.» s. IV, 3, 2005, pp. 30-72 (seconda parte)

Di Benedetto 2003: V. Di Benedetto, Omero, Saffo e Orazio e il nuovo Posidippo, «Prometheus» 29, 2003, pp. 1-16

Dettmer 1983: H. Dettmer, Horace: A Study in Structure, Hildesheim, Zürich, New York 1983

Draheim 1900: H. Draheim, Die Anordnung der Gedichte im 1. Bucher der Oden des Horaz,

«Wochenschr. für klass. Philol.» 46, 1900, coll. 1269-1270

Eisenberger 1980: F. Eisenberger, Bilden die horazischen Oden 2,1-12 einen Zyklus?, «Gymnasium» 87, 1980 , pp. 262-274

Esser 1976: D. Esser, Untersuchungen zu den Odenschlüssen bei Horaz, Meisenheim am Glan 1976

Fowler 1989: D. P. Fowler, First Thoughts on Closure: Problems and Prospects, «Mat. Disc.» 22, 1989, pp. 75-122 (= D. P. F., Roman Constructions. Readings in Postmodern Latin, Oxford 2000, pp. 239-283)

Fraenkel 1957 E. Fraenkel, Horace, Oxford 1957 (= ed. it. a cura di S. Lilla, premessa di S. Mariotti, Roma 1993)

Gowers (1993): E. Gowers, Horace, Satires 1.5: an inconsequential journey, «Proc. Cambr. Philol. Soc.» 39, 1993, pp. 48-66

Griffiths 2002: A. Griffiths, The Odes. Just where do you draw the line?, in T. Woodman, D. Feeney (edd.), Traditions \& Contexts in the Poetry of Horace, Cambridge 2002, pp. 65-79

Gutzwiller 1997: K. Gutzwiller, The Poetics of Editing in Meleager's Garland, «Trans. Amer. Philol. Ass.» 127, 1997, pp. 169-200

- 1998: K. J. Gutzwiller, Poetic Garlands. Hellenistic Epigrams in Context, Berkeley-Los AngelesLondon 1998

Harrison 2004: S. J. Harrison, Lyric Middles: the Turn at the Centre in Horace's Odes, in S. Kyriakidis, F. De Martino (edd.), Middles in Latin Poetry, Bari 2004, pp. 81-102

Heyworth 1995: S. J. Heyworth, Dividing poems, in O. Pecere-M.D. Reeve (edd.), Formative Stages of Classical Traditions: Latin Texts from Antiquity to the Renaissance, Spoleto 1995, pp. 117-148

Hutchinson 2002: G. O. Hutchinson, The Publication and Individuality of Horace's Odes Books 1-3, «Class. Quart.» 52, 2002, pp. 517-537

Irigoin 1993: J. Irigoin, Les éditions de textes, in O. Reverdin, B. Grange (edd.), La philologie grecque à l'époque hellénistique et romaine, "Entretiens de la Fondation Hardt, 40", Vandœuvres-Genève 1993, pp. 39-93

Johnson 2005: W. Johnson, The Posidippus Papyrus: Bookroll and Reader, in K. Gutzwiller (ed.), The New Posidippus. A Hellenistic Poetry Book, Oxford 2005, pp. 70-80

Kiessling 1881: A. Kiessling, Horatius I. Zur Chronologie und Anordnung der Oden, «Philol. Unters.» 2, 1881 , pp. $48-75$

Kiessling-Heinze 1960: Q. Horatius Flaccus, erklärt von A. Kiessling, I, Oden und Epoden, zehnte Auflage besorgt von R. Heinze, mit einem Nachwort und bibliographischen Nachträgen von E. Burck, Berlin 1960 (sechste Auflage erneuert von R. H., Berlin 1917)

Krevans 1984: N. Krevans, The Poet as Editor: Callimachus, Virgil, Horace, Propertius and the Development of the Poetic Book, Diss. Princeton 1984 
- 2005: N. Krevans, The Editor's Toolbox: Strategies for Selection and Presentation in the Milan Epigram Papyrus, in K. Gutzwiller (ed.), The New Posidippus. A Hellenistic Poetry Book, Oxford 2005, pp. 81-96

Kroll 1924: W. Kroll, Studien zum Verständnis der römischen Literatur, Stuttgart 1924 (= New York, London 1978)

La Bua 1999: G. La Bua, L'inno nella letteratura poetica latina, San Severo 1999

La Penna 1963: A. La Penna, Orazio e l'ideologia del principato, Torino 1963

Lefèvre 1995: E. Lefèvre, Die Komposition von Horaz' erstem Oden-Buch, in L. Belloni, G. Milanese, A Porro (edd.), Studia Classica Iohanni Tarditi oblata, Milano 1995, I, pp. 507-521

Lentini 1999: G. Lentini, Un carme allegorico in POxy 1788: il fr. 119 V. di Alceo, «Riv. Filol. Istr. Class.» 127, 1999, pp. 5-31

- 2006: G. Lentini, Un lamento da donne: il fr. 10 V. di Alceo, «Sem. Rom.» 2006 (in corso di stampa). Liberman 1993: G. Liberman, Autour de l'édition alexandrine d'Alcée, «Mél. Écol. Fran. RomeAntiquité» 105, 1993, pp. 1003-1013

- 1999: G. Liberman, Alcée, Fragments, I-II, Paris 1999

Lissarrague (1989): F. Lissarrague, L'immaginario del simposio greco, Roma-Bari 1989 (ediz. orig. Paris 1987)

Lowrie 1995: M. Lowrie, A Parade of Lyric Predecessors: Horace C. 1.12-18, «Phoenix» 49, 1995, pp. $33-48$

Ludwig 1957: W. Ludwig, Zu Horaz 2,1-12, «Hermes» 85, 1957, pp. 336-345

Luria 1947: S. Luria, Annotationes Alcaicae, «Par. Pass.» 2, 1947, pp. 79-87

Mendell 1965: C. W. Mendell, Latin Poetry. The New Poets and the Augustans, New Haven-London 1965

Miller 1991: P. A. Miller, Horace, Mercury, and Augustus, or the Poetic Ego of Odes 1-3, «Amer. Journ. Philol.» 112, 1991, pp. 365-388

Minarini 1989: A. Minarini, Lucidus ordo. L'architettura della lirica oraziana (libri I-III), Bologna 1989 Moritz 1968: L. A. Moritz, Some “Central” Thoughts on Horace’s Odes, «Class. Quart.» 18, 1968, pp. $116-131$

Musti 2003: D. Musti, Le simmetrie del testo (a proposito di Orazio, Carm. 1, 37), «Sem. Rom.» 6, 2003, pp. 107-114

Mutschler 1974: F.-H. Mutschler, Beobachtungen zur Gedichtanordnung in der ersten Odensammlung des Horaz, «Rhein. Mus.» 117, 1974, pp. 109-133

Nisbet-Hubbard 1970: R. G. M. Nisbet-M. Hubbard, A Commentary on Horace: Odes Book I, Oxford 1970

Nisbet-Hubbard 1978: R. G. M. Nisbet-M. Hubbard, A Commentary on Horace: Odes Book II, Oxford 1978

Nisbet-Rudd 2004: R. G. M. Nisbet-N. Rudd, A Commentary on Horace, Odes, Book III, Oxford 2004 Pardini 1991: A. Pardini, La ripartizione in libri dell'opera di Alceo. Per un riesame della questione, «Riv. Filol. Istr. Class.» 119, 1991, pp. 257-284

Pasquali 1920: G. Pasquali, Orazio lirico, Firenze 1920 (rist. xerogr. con intr. indici ed aggiornamento bibl. a cura di A. La Penna, Firenze 1964) 
Pöschl 1973: W. Pöschl, Die Dionysode des Horaz (c. 2,19), «Hermes» 101, 1973, pp. 208-230 Porro 1994: A. Porro, Vetera Alcaica. L'esegesi di Alceo dagli Alessandrini all'età imperiale, Milano 1994 - 1996: A. Porro, Carmi “di Mirsilo" e carmi "di Pittaco". Ancora sull'edizione aristarchea di Alceo, «Aev. Ant.» 9, 1996, pp. 177-192

Port 1926: W. Port, Die Anordnung in Gedichtbüchern augusteischer Zeit, «Philologus» 81, 1926, pp. 279-308

Porter 1987: D. Porter, Horace's Poetic Journey, Princeton 1987

Putnam 1969: M. Putnam, Horace carm. 1,20, «Class. Journ.» 64, 1969, pp. 153-157

-1973: M. Putnam, Horace's C. 3.30: the lyricist as hero, «Ramus» 2, 1973, pp. 1-19

Riese 1866: A. Riese, Horatiana, «Jahrbb. für klass. Philol.» 12, 1866, pp. 474-476

Rossi 1998: L. E. Rossi, Orazio, un lirico greco senza musica, «Sem. Rom.» 1, 1998, pp. 163-181

Rudd 1960: N. Rudd, Patterns in Horatian Lyric, «Amer. Journ. Philol.» 81, 1960, pp. 373-392

Salat 1969: P. Salat, La composition du livre I des Odes d'Horace, «Latomus» 28, 1969, pp. 554-574

Santirocco 1986: M. Santirocco, Unity and Design in Horace's Odes, Chapel Hill 1986

Seidensticker 1976: B. Seidensticker, Zu Horaz C.1, 1-9, «Gymnasium» 83, 1976, pp. 26-34

Serpa 1997: F. Serpa, voce "struttura”, in Enc. Or., II, Roma 1997, pp. 750-752

Simon 1895: J. A. Simon, Zur Anordnung der Oden des Horaz, in Festschrift der dreiundvierzigsten Versammlung Deutscher Philologen und Schulmänner, Bonn 1895, pp. 163-172

Skutsch 1963: O. Skutsch, The Structure of the Propertian Monobiblos, «Class. Philol.» 58, 1963, pp. 238-239

Slater 1976: W. J. Slater, Symposium at Sea, «Harv. Stud. Class. Philol.» 80, 1976, pp. 161-170

Stemplinger 1913: E. Stemplinger, Horatius, in RE, VIII.2, cc. 2336-2399 (1913)

Traina (1998): A. Traina, Introduzione a Orazio lirico: la poesia della saggezza, in Poeti latini (e neolatini). Note e saggi filologici, V, Bologna 1998, pp. 133-168 (ediz. or.: Orazio, Odi e Epodi, introd. di A. T., trad. e note di E. Mandruzzato, Milano $1997^{9}$ [1985ํㅣ, pp. 5-45)

van Rooy 1968-1972: C. A. van Rooy, Arrangement and Structure of Satires in Horace, Sermones, Book I, «Acta Class.» 11, 1968, pp. 38-72; 13, 1970, pp. 7-27 e 45-59; 14, 1971, pp. 67-90; 15, 1972, pp. 37-52 Van Sickle 1984: J. Van Sickle, Dawn and Dusk as Motifs of Opening and Closure in Heroic and Bucolic Epos (Homer, Apollonius, Theocritus, Virgil), in Atti del Convegno Mondiale Scientifico di Studi su Virgilio, Milano 1984, I, pp. 125-147

Vetta 2002: M. Vetta, Alceo, l'allegoria della nave e la configurazione di Mitilene arcaica, in M. S.

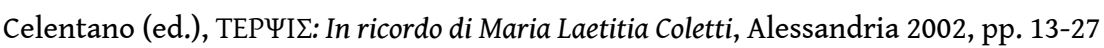

Watson 2003: L. C. Watson, A Commentary on Horace's Epodes, Oxford 2003

Wilamowitz 1914: U. v. Wilamowitz-Moellendorff, Neue lesbische Lyrik, «Neu. Jahrbb. Alt.» 33, 1914, pp. 225-247 (= Kleine Schriften, I, Berlin 1935, pp. 384-414)

Wili 1948: W. Wili, Horaz und die augusteische Kultur, Basel 1948

Zanker 1989: P. Zanker, Augusto e il potere delle immagini, Torino 1989 (ed. or. München 1987) 
Zetzel 1980: J. E. G. Zetzel, Horace's Liber Sermonum: the Structure of Ambiguity, «Arethusa» 13, 1980, pp. 59-77.

\section{NOTE}

1. Sulla struttura del I libro dei Sermones basti rinviare a van Rooy (1968-1972); Zetzel 1980.

2. Analogamente, si può dire, la funzione proemiale-divina era stata espressa da Virgilio attraverso il giovane deus (Ottaviano) nell'egloga di apertura delle Bucoliche.

3. Nel corso della raccolta la presenza di Saffo, e soprattutto di Alceo, si farà sempre più evidente, fino all'orgogliosa rivendicazione del carme 3, 30, 13-14 princeps Aeolium carmen ad Italos/deduxisse modos (una sorta di "colonizzazione" dalla Grecia all'Italia, che l'ecista-poeta Orazio ha guidato); cf. carm. 1, 26, 10-12; 2, 13, 24-28; 4, 3, 23; epist. 2, 2, 99. Non manca di essere coinvolto dal carme iniziale anche l'altro grande modello, quello di Pindaro, ma implicitamente, attraverso il gioco allusivo: Barchiesi 2000, pp. 171-172 (ed inoltre 1997a, pp. 729b-730a).

4. Per una stimolante rivisitazione del concetto pasqualiano, si rinvia a Cavarzere 1996.

5. Che Orazio possa essere stato influenzato al momento di ordinare i Carmina dall'edizione di Alceo è intuizione già presupposta dal Wilamowitz 1914, p. 231; cf. Pasquali 1920, ad es. pp. 201-202. Riguardo alla struttura editoriale dei Carmina, ci limitiamo qui a rinviare alle due specifiche voci dell'Enciclopedia Oraziana: Barchiesi 1997b ("sequenze"); Serpa 1997 ("struttura"); altra bibliografia menzioneremo più avanti.

6. Si rinvia a Pardini 1991; si aggiungano Liberman 1993; Porro 1994, spec. pp. 239-241; Porro 1996; Cucchiarelli 1997; Lentini 1999.

7. Basti ricordare il Damasippo della sat. 2, 3: quorsum pertinuit stipare Platona Menandro,/Eupolin, Archilochum, comites educere tantos? (11-12). Non abbiamo, d'altra parte, il modo di stabilire se Orazio si rendesse conto del fatto, ai nostri occhi ovvio, che Alceo non avrebbe mai potuto ragionare in termini di "edizione" (nei termini, almeno, editoriali e librari, dell'edizione alessandrina). Ma ad Orazio sarà comunque riuscita evidente la presenza di una mediazione ellenistica, soprattutto nell'eventualità che avesse accesso al ricco corredo di informazioni erudite e di cure critiche al testo di Alceo che dai filologi alessandrini derivava. Ad ogni modo, la forma editoriale alessandrina (e post-alessandrina) doveva apparire ad Orazio parte integrante della propria esperienza di lettore, inscindibile dalla fruizione dell'antico poeta - e, quindi, ragione poetica, essa stessa imitabile.

8. Basti rinviare, nello specifico, a Pardini 1991, pp. 259-260. Sulla possibilità di un confronto tra i carmi iniziali di Orazio e i carmi iniziali di Alceo ha richiamato l'attenzione Barchiesi 2000, spec. p. 172 (le cui osservazioni qui presupponiamo: vedi infra, n. 10). Sul primo "inno" di Alceo si veda La Bua 1999, p. 74.

9. Iam satis terris nivis atque dirae/grandinis misit Pater et rubente/dextera sacras iaculatus arcis/terruit urbem eqs. (carm. 1, 2, 1-4). Si può osservare che proprio Giove, nella forma naturistico-metaforica di "cielo", è la prima divinità in assoluto ad essere nominata da Orazio: sub Iove frigido (carm. 1, 1, 25): forse una attuazione, ironicamente diminuita, dello stereotipo arateo-virgiliano $A b$ Iove principium $($ ecl. 3,60$)$ ? Non tarderà, il secondo carme, a mostrare quale pericolo sia vivere sub Iove (tanto più se frigidus).

10. Cf. Barchiesi 2000, p. 172: «The two prominent gods in the list, Apollo and Hermes, are known to be the dedicatees of the two first poems in the first book of Alcaeus's collected songs [...]. Perhaps Horace is practising to become a new Alcaeus after all. [...] but in the meantime he recalls Alcaeus One, although $\kappa \alpha \tau$ ' ’ $v \tau i ́ \varphi \rho \alpha \sigma ı v ~ » ;$ cf. La discendenza materna (43 filius Maiae), compariva già nel modello alcaico, fr. 308, 3 V.; Mutschler, 1974, p. 126. 
11. Si aggiunga che, utilizzando il metro identificante di Saffo e del suo primo componimento (il già ricordato inno ad Afrodite, fr. 1 V.), con il secondo carme Orazio completa il binomio allusivo ai due auctores lesbii cui ha "appena" rinviato (nel concludere il carme 1,1). Sul nesso a distanza tra il carme 1, 2 e il carme 1, 10 si veda in special modo Santirocco 1986, pp. 44-46; Miller 1991, spec. p. 369.

12. Non si può, naturalmente, escludere che Venere/Afrodite comparisse già nel terzo componimento di Alceo, dedicato alle Ninfe figlie di Zeus Egioco (divinità acquoree ma "pastorali": Liberman 1999, II, p. 135), di cui si è conservato soltanto il verso iniziale Nú $\mu \varphi \alpha 1, \tau \alpha i ̀ \varsigma$

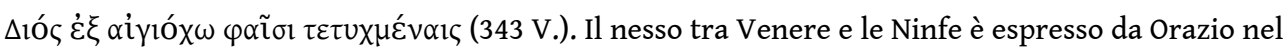
carme immediatamente successivo: iam Cytherea choros ducit Venus imminente luna,/iunctaeque Nymphis Gratiae decentes eqs. (1, 4, 5-6).

13. Basti ricordare Pasquali 1920, p. 79; cf. Nisbet-Hubbard 1970, p. 116; Cavarzere 1996, pp. 141-142.

14. Il ruolo metrico-inaugurale del carme 1, 9 non ha mancato di essere osservato da Lyne (1995), p. 96 (cf. anche pp. 95; 98-9). Nel nome del destinatario Thaliarchus (v. 8) sembra ritrovarsi,

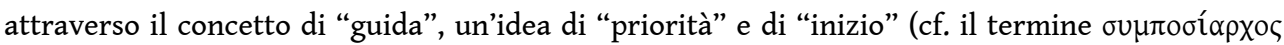
citato in Nisbet-Hubbard 1970, p. 121, ad loc.): $\theta \alpha \lambda$ í $\alpha$ è parola lirica per la "festa", e $\Theta \alpha \lambda i ́ n$ è una

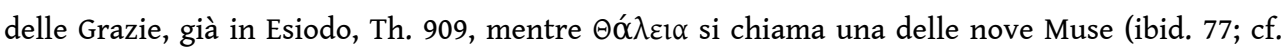
carm. 4, 6, 25 doctor argutae fidicen Thaliae; Verg. ecl. 6, 2; ma è attestata anche la forma $\Theta \alpha \lambda i ́ n$ in AP 9, 505, 7 [la Musa della commedia]). Si può pensare all'analogia con un nome proprio come

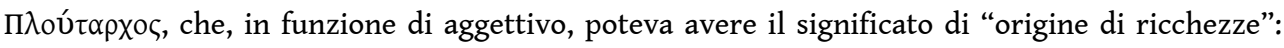
LSJ, p. 1423a, s.v.: dunque, il nome Taliarco potrebbe valere, anche, "iniziatore/guida della festa/ poesia" - appropriatamente per un poeta, come Orazio, che dà qui la sua prima prova di emulazione diretta da Alceo.

15. Basti qui rinviare, anche per la bibliografia, a Cavarzere 1996, pp. 143-147.

16. Il confronto non manca di essere registrato nel comm. di Nisbet-Hubbard 1970, p. 130 ad loc.

17. Sui molteplici nessi che collegano il carme 1, 9 al carme 1, 10 si veda Miller 1991.

18. Ben nota è la rilevanza nelle raccolte poetiche augustee del 5, del 10 e dei loro multipli: Kiessling 1881, p. 73; Skutsch 1963, p. 239. Nel caso dei Carmina, un criterio a base decimale è stato utilizzato sistematicamente, per interpretarne la struttura, da Belling 1903, e, in tempi ben più recenti, da Griffiths 2002 (discusso in Cucchiarelli 2003). Da tener presente il fatto che cinquedieci è numero editoriale ben testimoniato nelle collezioni liriche dei modelli greci: si veda Liberman 1999, II, pp. 203-204, n. 41 (ad T LI), dove è citata la testimonianza di Anth. Pal. 9, 239 (riguardo ad Anacreonte); in dieci libri doveva essere la stessa edizione alessandrina di Alceo: Irigoin 1993, pp. 47-48.

19. Vale la pena di notare che sull'otto, il numero pari più prossimo alla decina, si attesta anche la complessiva raccolta dei Sermones (10 satire del libro I + 8 del libro II, per un totale di 18 satire); ma l'insieme di Sermones ed Epodi, a ulteriore conferma della loro stretta interrelazione, dà, ancora una volta, un multiplo di 5 , cioè 35 . Il raddoppio della decina, invece, sarà ricercato da Orazio per la prosecuzione del suo sermo, e per la sua ultima opera pubblicata come raccolta, le venti Epistulae.

20. La serie di ragioni che abbiamo illustrato, assieme ad altre che aggiungeremo più avanti (in special modo l'uso della strofe saffica a segnare i confini editoriali della raccolta: cf. infra), se inducono a considerare il carme 1, 10 come "conclusivo" del primo grande movimento decimale del libro, nulla tolgono alla ormai tradizionale definizione di "Paradeoden", che, essendo di natura specificamente metrica, deve restare ristretta ai primi nove componimenti (cf. ad es. Seidensticker 1976). Non convincono, d'altra parte, le ragioni a suo tempo addotte da Kiessling 1881, p. 63, per estendere ai primi dodici carmi il numero delle Paradeoden, in special modo per quanto riguarda le particolarità metriche del carme 1, 10 (Santirocco 1989, p. 42; Minarini 1989, p. 26, n. 3; cf. Nisbet-Hubbard 1970, p. xliv; Rossi 1998). Tra i sostenitori della suddivisione 1-12, si 
ricordino ancora Port 1926, p. 301; Porter 1987, p. 15. Considerano la sequenza iniziale estesa ai carmi 1, 1-10, tra gli altri, Mendell 1965, p. 140; Stemplinger 1913, c. 2372; Mutschler 1974. A noi sembra ben misurato, in particolare, l'atteggiamento di Santirocco 1984, pp. 42-43 (cf. infra); si tengano presenti, infine, le osservazioni di Lowrie 1995, p. 34.

21. Cf., naturalmente, Verg. ecl. 6, 6-7. Sulla collocazione "al mezzo" nei Carmina si rinvia al recentissimo Harrison 2004.

22. Si veda infra. Riguardo alla collocazione "strategica" della satira 1, 6 si veda Coffey 1976, p. 81; Zetzel 1980, p. 59 e n. 3; pp. 66-67 e n. 45; Gowers 1993, p. 50.

23. Su Orazio come Alceo "dimidiato" si rinvia ancora a Barchiesi 2000, p. 169.

24. Cf. Diod. 4, 7, 4; Corn. 14, p. 16, 20-17, 3 L. In Ovidio, al principio del libro V dei Fasti, sarà proprio Polyhymnia a prendere autorevolmente la parola su questioni teologico-eziologiche (vv. 11-52).

25. Si rinvia, anche per la ricca bibliografia, al noto lavoro di Zanker 1989.

26. Il non nominato Marte, cui Orazio allude con una trasparente perifrasi (35-40), completa, accanto a Venere, la coppia delle divinità fondatrici (36 auctor), e nel contempo riporta il lettore al tema minaccioso della guerra.

27. A conferma della sua "inizialità", il carme 1, 2 si fa qui confronta bile con il proemio delle Georgiche, e con la figura di principe-dio che, analogamente, vi era invocata: novum tardis sidus te mensibus addas (georg. 1, 32).

28. La rilevanza di queste tematiche nel libro I dei Carmina è ben percepita da Hutchinson 2002, p. 531.

29. Si rinvia a Pardini 1991, pp. 259-260; 283, e a Porro 1994, spec. pp. 145-146. Questo dato è riconosciuto anche da chi, come Liberman, è piuttosto scettico sulla suddivisione dei carmi di Alceo tra $\sigma \tau \alpha \sigma \iota \omega \tau \iota k \alpha ́$ e non- $\sigma \tau \alpha \sigma \iota \omega \tau \iota k \alpha ́$ : cf. 1999, I, p. li. Si aggiunga che non sembra si possa affermare, come invece fa Liberman, ibid. e n. 171, che l'argomento del brevissimo fr. $215 \mathrm{~V}$. dovesse essere estraneo al tema stasiotico; riguardo, inoltre, alla possibile interpretabilità stasiotica del fr. $10 \mathrm{~V}$. (anch'esso citato da Liberman a favore della propria tesi), si veda Lentini 2006.

30. Per questa interpretazione si veda la n. 59 di Liberman 1999, II, p. 205 ad loc.

31. L'osservazione risale a Luria 1947, pp. 82-83. Dunque, i Dioscuri come divinità pronte a

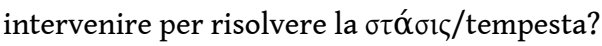

32. Si veda Liberman 1999, I, p. 30; Vetta 2002, p. 23. In una prospettiva allegorico-politica

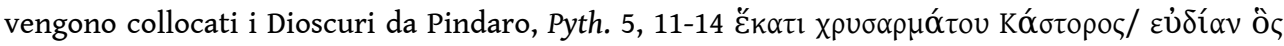

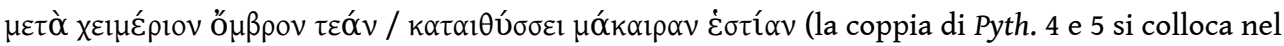
contesto delle sedizioni aristocratiche che Arcesilao aveva dovuto affrontare: cf. Pyth. 4, inscr. a). È ipotesi possibile che gli inni ai Dioscuri figurassero anch'essi nel libro I dell'edizione: Liberman 1999, I, p. lv.

33. Nel carme 1, 2, del resto, Venere ha "appena" ricoperto il ruolo, "storico-politico", di salvatrice di Roma (vv. 33-34).

34. Nei Carmina, e in generale nella cultura augustea, Ercole è piuttosto figura positiva di civilizzatore, e, quindi, modello divino per lo stesso principe: cf. infra, n. 43.

35. È forse rilevante che, a chiudere la prima parte del carme 1, 3 (ben divisibile in due metà di 20 vv.), ricompaia nel toponimo, etimologicamente, l'idea della "vetta" e del "fulmine": infamis scopulos Acroceraunia (20); cf. 1, 2, 2-3 rubente/dextera sacras iaculatus arces. La seconda parte del carme 1, 3 è aperta dalla divinità (v. 21 nequiquam deus abscidit), e con i fulmina del v. 40, come abbiamo visto, esso si conclude. Ancora, metereologia e divinità.

36. Il dettaglio allude al riprendere della navigazione, come nell'epigramma di Leonida $(A P, 10,1)$, già citato da Cicerone durante i concitati momenti della guerra civile (ad Att. 9, 7, 5; NisbetHubbard 1970, p. 59 ad loc.). Sembrerebbe che la tecnologia umana, qui rappresentata dalle 
machinae, dopo esser stata tanto duramente criticata nel carme 1, 3, ora rientri armonicamente nel ciclo della natura.

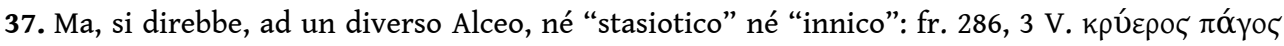

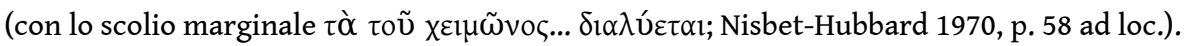

38. Cf. supra.

39. Che in ventos.../deproeliantis si percepisca la memoria di Alceo, fr. 208a, 1 V. è ipotizzato da Cavallini 1979, p. 515 (cf. anche 1996, p. 628b). Tanto più rilevante riuscirebbe l'inclusione nel carme 1, 9 di questo dettaglio, dal momento che esso, identificante (e iniziale) del grande modello allegorico alcaico, non viene ripreso nell'apertamente emulativo carme 1, 14 .

40. Nel carme 1, 11, Giove e l'inverno figurano in una prospettiva strettamente esistenziale: seu pluris hiemes seu tribuit Iuppiter ultimam,/quae nunc oppositis debilitat pumicibus mare/Tyrrhenum eqs. (4-6).

41. Si noti come il movimento retorico-sintattico del carme 1, 9 (qui simul/stravere ventos ... nec cupressi/nec ... agitantur orni) sia svolto nel carme 1, 12, e ampliato, al positivo: quorum simul... / stella refulsit, / defluit ... /concidunt ... /et ... /unda recumbit.

42. Il framm. alcaico è ricordato da Nisbet-Hubbard 1970 nel comm. al carme 1, 3, 2 (p. 46), ma non nel comm. a 1, 12, dove vengono avanzati altri confronti, tra cui quello con l'inizio di Teocrito, Id. 22 (si veda spec. p. 153, ad 27 quorum).

43. Cf. 3, 3, 9-12; 4, 5, 33-36; 4, 8, 29-33; ed anche epist. 2, 1, 5-6. Nello stesso luogo del carme 1, 12,

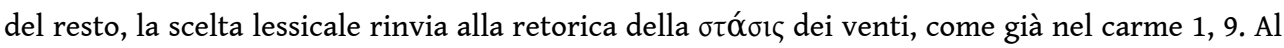
risalto che nel carme 1, 12 i figli di Leda ricavano dal fatto di essere l'exemplum divino più dettagliato del carme (due strofe: vv. 25-32), si unisce la collocazione al centro numerico dell'ode (che è lunga 60 versi).

44. Al lettore che avesse ravvisato in Quid prius dicam solitis eqs. (13) una variazione del concetto tradizionale di Ab Iove principium giunge, esplicita, la conferma qualche verso più avanti: nec viget quicquam simile aut secundum (18). Sul ruolo, anche editorialmente strategico, di Giove nei Carmina si veda Moritz 1968.

45. Si aggiunga che le tre strofe del carme 1, 20 sembrano segnare una tappa nel liber anche dal punto di vista tematico, con l'allocuzione a Mecenate, l'invito a bere e il "modesto vino sabino", ovvia metafora della poesia stessa di Orazio. Si comprenderà, a questo punto, perché ai nostri occhi non possa che apparire sorprendente la notazione di Nisbet-Hubbard 1970, p. 146, che così concludono l'introduzione del carme 1, 12: «Metre: Sapphic (not altogether appropriate for the matter in hand)». Abbiamo infatti visto come la scelta della strofe saffica, per un carme dal tema elogiativo come 1, 12, si colleghi a importanti linee strutturali che attraversano il libro, oltre che rinviare al modello di Alceo. Ma su questi argomenti non mancheremo di tornare.

46. Seu pluris hiemes seu tribuit Iuppiter ultimam (4). Assai sensibile al significato simbolico di questi versi, all'interno del mondo dei Carmina, si è mostrato Rudd 1960, spec. p. 374.

47. Sul significato personalistico, e non genericamente istituzionale-politico (la "nave dello Stato"), che Orazio sembra, almeno nella nostra interpretazione, aver attribuito alla propria allegoria, si rinvia a Cucchiarelli 2004; 2005.

48. Per il caso del carme 4, 1 , in cui Orazio passa dalla divinità "alcaica" all'evocazione di un simulacro, si veda Barchiesi 2000, pp. 172-173.

49. Cf. Cucchiarelli 2005, pp. 40-46.

50. Mercurio è celer, nel carme 2, 7, perché è il dio del cambiamento (cf. 1, 2, 41 mutata iuvenem figura). Vale forse la pena di osservare che l'asclepiadeo terzo, il metro del carme 1, 14, verrà riutilizzato da Orazio, nella prosecuzione del liber, per una rassicurante, e ottavianea, raffigurazione del favore divino (ben diversamente, dunque, dal carme 1, 14): ci riferiamo al carme 1,21 , in cui un coro di fanciulli e fanciulle è chiamato a celebrare la triade Diana-ApolloLatona, e che sulla figura salutifera di Apollo si conclude - hic bellum lacrimosum, hic miseram famem/pestemque a populo et principe Caesare in / Persas atque Britannos/vestra motus aget prece 
(13-16). Si potrebbe azzardare che i quattro carmi in asclepiadeo terzo del libro I studiatamente si corrispondano: 1, 5 e 1, 23, entrambi brevi variazioni sul tema erotico, ai due estremi; 1,14 e 1, 21 tra di essi (piuttosto sporadiche le restanti occorrenze nel corpus lirico: 3,$7 ; 3,13 ; 4,13$ ). Si aggiunga che il carme 1, 5 anticipa in termini erotici l'immagine del naufragio: heu quotiens fidem/ mutatosque deos [gli dèi!] flebit et aspera/nigris aequora ventis/emirabitur insolens (5-8); me tabula sacer/votiva paries indicat uvida/suspendisse potenti/vestimenta maris deo (13-16).

51. È invece concentrata sulla nave, sulla fuga e sulla guerra la rievocazione di Alceo nel carme 2, 13, 27-8.

52. Cf. Slater 1976; Lissarrague 1989. Naturalmente, era anche possibile bere a bordo di una nave come in Archiloco, fr. $4 \mathrm{~W}$.

53. Cf. Cucchiarelli (2005), spec. pp. 31-32.

54. La corrispondenza emotivo-caratteriale, nella persona del poeta, si riflette a livello di riscontro psicologico nel testo: cf. epod. 1, 17-18 comes minore sum futurus in metu,/qui maior absentis habet con carm. 1, 14, 18 nunc desiderium curaque non levis (l'assenza accende la preoccupazione).

55. L'ambientazione festiva del carme realizza quanto nell'epodo 9 doveva restare al livello di desiderio (si noti: carm. 1, 37, 4 dapibus epod. 9, 1 ad festas dapes). Si comprenderà perché, dal nostro punto di vista, debba apparire poco felice la notazione di Nisbet-Hubbard al v. 5 antehac, p. 412: «Horace professed to drink Caecuban immediately after the battle of Actium (epod. 9. 36); but as the symposia in both places are purely literary, the inconsistency is easily explained». Piuttosto, sembra che Orazio abbia congegnato con molta attenzione la rete di rapporti tra l'epodo e il carme, e sarebbe stato opportuno menzionare ad loc. l'inizio dell'epodo 9, piuttosto che la fine: soprattutto, il Cecubo che chiude, in termini di eventualità, l'epodo 9 , va tenuto distinto da quello in apertura, che è repostum.

56. Non si è mancato di osservare l'opposizione, geografico-culturale, oltreché "enologica", tra il Cecubo e il Mareotico (si veda Nisbet-Hubbard al v. 5, p. 412). Sulla studiatissima costruzione retorica e strutturale del carme 1, 37 si veda il contributo, "fraenkeliano", di Musti 2003.

57. Dunque, nausea ha il significato proprio, e si direbbe inevitabile in un contesto "navale", di "mal di mare": si rinvia, anche per la bibliografia, a Watson 2003, pp. 310-311, ed inoltre pp. $335-336$, n. al v. 35. Non riesce persuasiva nemmeno l'impostazione di Slater1976, spec. pp. 168-9 (un articolo che pure ha il merito di aver valorizzato le intersezioni tra la nave e il simposio, e di aver interpretato l'epodo 9 come poesia specificamente simposiale: ma cf. già Bartels 1973).

58. A ben vedere, nemmeno è dirimente la notizia, su cui ha insistito Fraenkel, che Mecenate fosse rimasto a Roma al tempo della battaglia di Azio: Orazio potrebbe voler inviare all'amico una sorta di "dispaccio" in tempo reale, immaginando il momento tanto atteso in cui si sarebbero ritrovati, a Roma, per festeggiare la vittoria. E resta il fatto che il libro degli Epodi, pubblicato dopo Azio, sembra voler deliberatamente valorizzare il concreto impegno bellico di Mecenate, già semplicemente con l'incipit, che vale la pena ancora una volta di ricordare: Ibis Liburnis inter alta navium,/amice,propugnacula etc.

59. Un altro attraente confronto, sul tema politico, è quello tra l'epodo 7 e il carme 1, 14: si noti la corrispondenza nell'idea di una terribile forza "trascinante": epod. 7, 1 ruitis; 13 rapit $\approx$ carm. 1, 14, 1 referent.

60. Secondo quanto già osservato da Kroll 1924, p. 226.

61. Della ricchissima bibliografia, già raccolta e discussa da Dettmer 1983 e da Minarini 1989, ricordiamo in particolare i pionieristici lavori di Riese 1866; Simon 1865; Draheim 1900, che non hanno mancato di valorizzare, da diversi punti di vista, la presenza di strutture decimali nell' "architettura" dei Carmina; si aggiunga, più di recente, Salat 1969. Preziosi per comprendere la struttura del corpus oraziano si stanno mostrando gli studi sul libro ellenistico, recentemente ancor più stimolati dalla pubblicazione del "nuovo" Posidippo: si rammentino, in particolar modo, Gutzwiller 1997; 1998; Argentieri 1998; Johnson 2005; Krevans 2005. 
62. Sul concetto di "estremità" insiste la parola in chiusa, imis; cf. ars 152 primo ne medium, medio ne discrepet imum; 126; Th.l.L., VII.1, 1403, 18-25. Si aggiunga che gli dèi inferi sono ben adatti a comparire in una "chiusa"; su di un tono "oscuro" Virgilio aveva concluso le Bucoliche: cf. ecl. 10, 75-77 (la triplice ripetizione di umbra; la menzione di Hesperus); Van Sickle 1984; Fowler 1989 , spec. p. 88 , n. 56 ; p. 102 (= 2000, p. 252 , n. 56 ; p. 264). Sulla cura da Orazio impiegata nel predisporre la chiusa dei singoli carmi si rinvia a Esser 1976.

63. Quest'ultima “osservazione fu avanzata dal Belling 1903, ma all'interno di una ipotesi sulla struttura del libro I che non è riuscita, a ragione, persuasiva (Minarini 1989, p. 34).

64. Particolarmente rilevanti, dal nostro punto di vista, le osservazioni di Santirocco 1984, spec. pp. 42-43.

65. In linea di principio non si può escludere, naturalmente, per il carme 1, 11 la presenza di echi o allusioni da Alceo, dal momento che dell'inno alle Ninfe si è conservato soltanto il primo verso (fr. 343 V.). Un nesso tematico tra Mercurio e le Ninfe (e Venere) si osserva nel breve "inno" a Venere di 1, 30, 5-8, su cui cf. infra. A rinserrare ulteriormente il nesso tra il carme 1,10 e il carme 1, 11, non può essere trascurato un preciso effetto sintagmatico: l'"inno" a Mercurio si conclude con l'immagine del dio "psicopompo", grato anche agli dèi inferi (17-20 tu pias laetis animas reponis/.../...superis deorum/gratus et imis), mentre l'ode a Leuconoe si apre con il pensiero della morte che gli dèi hanno stabilito: Tu ne quaesieris (scire nefas) quem mihi, quem tibi/finem di dederint, Leuconoe (1-2); si noti il ritorno fonico-retorico del tu ad inizio di verso.

66. Può essere utile ricordare come all'inizio dell'epodo 11, subito a seguire la sequenza degli epodi 1-10, Orazio si fosse concesso un distanziamento metapoetico (1-2 ...nihil me sicut antea iuvat/ scribere versiculos): anche gli Epodi, dunque, rimarcavano - e non soltanto editorialmente (il cambio di metro) - il limite del dieci.

67. Atteggiamento analogo si può riconoscere nel Virgilio dell'Eneide, che sembra aver voluto evitare di rendere troppo netta la cesura tra le due metà del poema: Fowler 1989, p. $95(=2000$, pp. 257-258). La poesia augustea, del resto, tende generalmente ad evitare incisioni troppo nette: si pensi a come, per restare alla tecnica versificatoria, sia evitata, se non per effetti particolari, la dieresi (la disposizione delle parole deve contrastare con i singoli confini dei piedi metrici, non sovrapporsi ad essi; la poesia deve essere "levigata", ad unguem).

68. Mentre la struttura delle Paradeoden ha trovato, almeno nelle sue linee essenziali, il consenso della maggior parte degli studiosi, notevole indecisione, e divergenza di opinioni, sussistono riguardo alla parte restante del libro I: si rammentino le osservazioni di Minarini 1989, p. 26.

69. Un preciso significato poetologico nel carme 1, 20, oltre che nel conclusivo carme 1, 38, è stato riconosciuto da Putnam 1969; si aggiungano Commager 1957; 1962, p. 326; Mutschler 1974, pp. 120-21 (che osserva le diverse analogie, funzionali e formali, tra il carme 1, 20 e il carme 1, 38); ed inoltre Lefèvre 1995, spec. p. 513.

70. Non sfugga che 1,22 , essendo in strofi saffiche come 1,20 , stabilisce una cornice omometrica, attorno al confine del 20 , che è analoga a quella stabilita dalle saffiche di 1,10 e 1,12 . La comunanza nel metro saffico tra 1, 10;1, 20;1, 30 è stata osservata, in special modo, da Draheim 1900.

71. L'altro, unico, componimento del libro I che si ferma a otto versi è il carme 1,11 (che, però, è nel metro "lungo" dell'asclepiadeo maggiore).

72. Si aggiunga che il nome di Mercurio compare piuttosto inaspettato, nel carme 1, 30, tanto da aver sollevato le perplessità degli interpreti (si veda Nisbet-Hubbard 1970, p. 344 ad loc.).

73. Nel medesimo carme 1,32 potrebbe riverberarsi la memoria del grande "peana" che fungeva da "proemio" ad Alceo: o decus Phoebi et dapibus supremi/grata testudo Iovis [...]/[...] mihi cumque salve/rite vocanti (13-16). Sembra infatti che la connessione tra Apollo e l'arte della lira fosse tra i temi di Alceo 1, stando alla testimonianza di Plutarco, de mus. 1135f (cit. dalla Voigt, p. 298): ov̉...

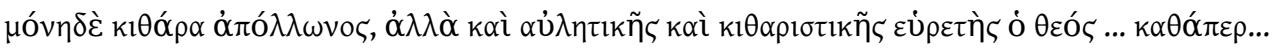

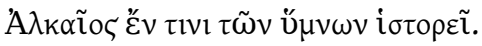


74. Sulla particolarissima sequenza innica dei carmi 1, 30-31-32 si ricordi quanto già osservava il Pasquali 1920, p. 147.

75. vv. 4-5 iterare cursus/cogor relictos (in favore della congettura relectos si vedano NisbetHubbard 1970, p. 380 ad loc.).

76. Altri casi nel libro I, oltre a 1, 34-35, sono 1, 16-17 e 1, 26-27. Una tale, occasionale, deroga al criterio della varietas metrica non manca del sostegno di un caso almeno, a quanto possiamo vedere, nell'edizione alessandrina di Alceo: gli attuali frr. 68-69 V. (in saffiche: POxy. 1234; 1360). Non crediamo, naturalmente, all'ipotesi di chi vorrebbe riunire in un unico carme tutte le coppie omometriche del libro I, in modo di ridurne il numero alla cifra "tonda" di 35 (ci riferiamo a Griffiths 2002; infra, n. 93).

77. Sul nesso a distanza tra 1, 2 e 1, 37 si vedano, più di recente, Lefèvre 1995, p. 509; Hutchinson 2002, p. 531.

78. Assieme a 4, 1, 28, sono, queste, le uniche occorrenze del tema Sal- nei Carmina (se si guarda all'intero corpus oraziano, si aggiunga epist. $2,1,86)$. Ma da confrontare, tra i due carmi, è tutto lo scenario lietamente simposiale.

79. Sulla comunanza tematica dei carmi 1,$36 ; 1,37 ; 1,38$, tutti "Trinklieder", aveva insistito già Port 1926, p. 299 (ma cf. Kiessling-Heinze 1960, p. 151); sul significato poetologico del carme 1, 38 si ricordi Fraenkel 1957, pp. 297-299. Il finale simposiale del libro I anticipa il pre-finale, esplicitamente bacchico, del libro II: vedi infra.

80. Tra gli effetti "ultimativi" si dovrebbe forse aggiungere la ripresa del celebre epigramma con cui si conclude lo Stéphanos di Meleagro (AP 12, 257 = 129 G.-P.): cf. Krevans 1984, p. 365; Barchiesi 2005, p. 325. Si aggiunga che kopwví s significa "corona" in un frammento di Stesicoro (187, 3 PMGF); cf. Bing 1988, p. 34. Dunque, con la scelta del termine corona $(1,38,2)$, posto a fine verso come ko $\omega$ wí́ in Meleagro, Orazio potrebbe aver voluto alludere puntualmente al modello ellenistico, anche per il significato, oltre che al livello della pura sociabilità fonica.

81. È stato ipotizzato, ad esempio, che nel libro I fossero confluite le "eccedenze", per così dire, degli altri libri: Port 1926, p. 299. Sul problema posto dal numero "atipico" di 38 si vedano le osservazioni di Fowler 1989, pp. 97-98 (= 2000, p. 260).

82. Tra i primi ad osservare l'alternanza di metri nel libro II fu Riese 1866; ma si ricordi in special modo Ludwig 1957; cf. Hutchinson 2002, p. 532. È interessante che l'alternanza alcaica-saffica sia anticipata dalla "coppia" dei carmi 1, 37 (alcaiche) e 1, 38 (saffiche): il nesso tra 1, 38 e 2, 1 fu già osservato, in una prospettiva strettamente tematica, da Commager 1962, p. 313, n. 17.

83. Su di un altro piano, esistenziale-erotico, dinamico è anche l'attacco del IV libro: Intermissa, Venus, diu/rursus bella moves $(4,1,1-2)$.

84. Cf. supra.

85. Del resto, con una parola di "movimento", come sì è visto, il libro II si è aperto; e non di rado in chiusa Orazio colloca termini di moto (o fuga): cf. ad es. epod. 16, 66;17, 81; ed anche sat. 2, 8, 93.

86. Cf. Nisbet-Hubbard 1978, pp. 5-6.

87. Dove però, si noti, il nome di Mecenate, che nel carme 2, 12 appare "soltanto" al v. 12, è presente già nel primo verso. Dunque, ha buone ragioni Eisenberger 1980 di valorizzare il carme 1, 12 come "inizio" della seconda parte del libro (cf. Minarini 1989, p. 133). Soltanto, questa forma editoriale sembra convivere con la struttura editoriale, valorizzata da Nisbet-Hubbard, cit., non porsi rispetto ad essa come alternativa. Che il libro II si rifiuti ad una "esatta" suddivisione è stato osservato da Krevans 1984, p. 368.

88. Non senza che Orazio stabilisca un continuo contrappunto dato dalla dimensione individuale dell'esistenza: si veda il carme 1, 16, 1-4 Otium divos rogat in patenti/prensus Aegaeo, simul atra nubes/condidit lunam neque certa fulgent/sidera nautis (si noti l'exemplum nautico, e il riferimento alle stelle che indicano la via ai marinai).

89. Si rammenti ad es. la chiusa del carme 1, 10: supra, p. 00, n. 62. 
90. Basti rinviare a Pasquali 1920, pp. 11-12; si aggiungano, dai loro diversi punti di vista, Santirocco 1986, p. 101; Porter 1987, pp. 145-146. Non sfugga l'effetto "accorpante" dell'omometria che unisce 2, 19 a 2, 20, entrambi in alcaiche. Uno stretto legame tra i penultimi carmi dei tre libri, cioè 1, 37; 2, 19; 3, 29, è ipotizzato da Pöschl 1973, p. 210.

91. Si presuppone qui Traina 1998 (= 1985); cf. infra, n. 107.

92. Dunque, le tre sequenze iniziali di Carm. 1-3 sono tutte diversamente identificate dal metro: varietà (libro I); alternanza (libro II); omometria (libro III); cf. Krevans 1984, p. 380. Non è da trascurare anche una certa confrontabilità nel numero dei versi, più evidente nel caso dei primi due libri (1, 1-10: 276 vv.; 2, 1-10: 264 vv.; 3, 1-6: 336 vv.).

93. Questa ipotesi è stata, in tempi più recenti, difesa da Griffiths 2002 (già presso Heyworth 1995, pp. 140-145); possibilista riguardo alla proposta di Griffiths si è mostrato Cairns 1995, pp. 128-129. In realtà, essa ha una storia molto lunga, già, almeno, ottocentesca: per una raccolta bibliografica si veda Minarini 1989, pp. 144-145. Ma a noi non sembra che Orazio abbia voluto tentare il genere del carmen perpetuum (dal quale prende le distanze in 1, 7, 5-6).

94. Sulla funzione del carme 3, 4, si vedano, tra gli altri, Port 1926, p. 341; Wili 1948, p. 207; La Penna 1963, p. 95, n. 2. La stessa affermazione con cui il carme 3, 4 inizia ...dic, age, tibia/regina longum Calliope melos (1-2), si comprende soltanto se Orazio ragionava in termini di singoli carmi: lo conferma il fatto che il carme 3, 4 sia effettivamente un longum melos (il più lungo del ciclo, con i suoi 80 versi).

95. Sulla possibilità di far rientrare il carme 3, 1 nella forma dell'inno, si veda Cairns 1995, pp. 97-100.

96. Basti osservare la comune parola di incipit, Mercuri, e l'immediata menzione della testudo (3, 11, 3-6; cf. 1, 10, 6).

97. Sul tono umoristico del carme 3, 21 basti rinviare a Nisbet-Rudd 2004, pp. 246-247. È

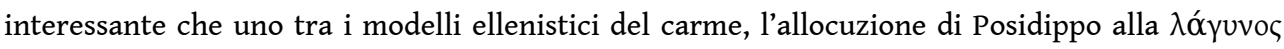
(AP 5, 134 = HE 3054-3057 Gow-Page), potesse occupare il ruolo di apertura nel ciclo introduttivo dello Stéphanos di Meleagro: Gutzwiller 1997, p. 173.

98. Sul senso di closure delle ultime tre odi del libro III, diversamente ottenuto, ha insistito Santirocco 1984, p. 149. Già nel finale del libro I, come abbiamo visto, si affacciava il tema del "bere insieme" (supra, pp. 00 e n. 79). Se 1, 37 si apriva con l'esortazione a bere, ad attingere dal Cecubo d'annata (5-6 antehac nefas depromere Caecubum/cellis avitis), similmente, con una ripresa letterale, l'avvio del carme 3, 28: Festo quid potius die/Neptuni faciam? prome reconditum,/Lyde, strenua Caecubum (1-3). Con il tema del simposio, in una allocuzione a Mecenate, si era conclusa già la seconda decina del libro I, nelle saffiche del carme 1, 20: Vile potabis modicis Sabinum/ cantharis [...]/care Maecenas eques (1-5); cf. 3, 29, spec. 1-5 [...] tibi/non ante verso lene merum cado/ cum flore, Maecenas, rosarum eqs.

99. Naturalmente, Nox è una divinità particolarmente adatta alla chiusa (notturna?) di un canto alternato, e, potenzialmente, di un libro poetico: tanto più, dunque, nenia, posto in ultimissima posizione, collabora all'effetto di closure; si ricordi Verg. ecl. 1, 83 maioresque cadunt altis de montibus umbrae; 10, 75-77 (supra, p. 00, n. 62).

100. Riguardo al rapporto tra i carmi 1, 1 e 3, 29 Nisbet-Rudd 2004, p. 345, richiamano l'analogo caso delle Epistole, in cui la 1 e la 19 sono entrambe dedicate a Mecenate. Nel terzo libro il dedicatario Mecenate ha già occupato un luogo esposto, aprendone la seconda metà con il carme 1, 16. Nel libro I, invece, nel suo nome si era conclusa la seconda decina (carme 1, 20).

101. Subito prima che si innescasse la sequenza finale, nella conclusione del carme 3, 27, era stato già introdotto il tema della fama immortale, attraverso la vicenda mitica di Europa: [...] tua sectus orbis/nomina ducet (75-76). Nel caso della fanciulla, audax, l'attraversamento del mare ha segnato l'inizio di un destino glorioso: vv. 17-28, spec. 18-20 ego quid sit ater/Hadriae novi sinus et quid albus/ peccet Iapyx. L'uso degli asclepiadei katà stíchon, che compaiono nella raccolta in tre libri esclusivamente in 1,1 e 3,30 , è stato da tempo riconosciuto come uno dei più chiari segnali 
“editoriali" presenti nel corpus lirico oraziano: cf. ad es. Ludwig 1961; Putnam 1973; Hutchinson 2002, p. 526 (ma cf. già Kiessling-Heinze 1960, p. 2; ed inoltre p. 429). L'unico altro impiego di questo metro, nel carme 4, 8, sembra essere anch'esso strutturalmente significativo, collocato al centro, o "quasi-centro" del IV libro (infra, p. 00, n. 103), e caratterizzato da un tema adatto ad una chiusa (il valore specifico della poesia, nel confronto con le altre arti; si noti anche la scelta dell'ultima parola, exitus, nel v. 34: cf. epod. 17, 81). Un confronto, illuminante, tra il carme 3, 30 e Posidippo, epigr. 118 Austin-Bastianini è ora osservato da Di Benedetto 2003 (per altri possibili riscontri si veda Gutzwiller 1998, p. 44).

102. Cf. ad es. 4, 2, 45-60 (il trionfo di Augusto); il carme 4, 5 ad Augusto; il carme 4, 6 ad Apollo.

103. Si osservi che, dato il numero complessivo di 15 , il carme 4,8 potrebbe essere considerato "centrale" (o, meglio, "semi-centrale") all'interno del libro. D'altro lato, anche la posizione decimale sembra essere rimarcata, come nel libro I, dalla collocazione in sede 1, 10 di un breve carme (di gran lunga il più breve del libro, con i suoi otto versi: otto erano anche i versi del carme 1, 30; cf. supra).

104. Analogo accorgimento in Polibio: si veda Canfora 1974, p. 13.

105. Ibid., p. 14.

106. Già nel grande modello virgiliano, Orazio poteva assistere al nesso tra l'inizio e la fine, addirittura ad unire due opere diverse, Bucoliche e Georgiche: ci riferiamo naturalmente alla chiusa di quest'ultime $(4,466$; cf. ecl. 1, 1), con le osservazioni di Fowler 1984, pp. 83-84 (= 2000, p. 247).

107. Cf. Traina 1998, spec. p. 154 (=1985, p. 28).

108. Un uso "razionalizzante" dei numeri nove, dieci e undici, rispettivamente, in 3, 19, 11-17; carm. saec. 21-22; epist. 1, 20, 27-28 (l'età del poeta, nel sigillo del libro I delle Epistole).

109. Si ignora, come è ovvio, se Orazio avesse voluto predisporre una qualche collocazione per il Carme secolare all'interno del proprio corpus lirico: opinione corrente è che vi sia stato inserito dopo la morte del poeta. È, ad ogni modo, interessante osservare che esso avrebbe potuto rappresentare un perfetto proemio all'intera raccolta dei Carmina: sebbene in saffiche, e non in alcaiche, anche Orazio avrebbe potuto "iniziare", al pari di Alceo, nel nome di Apollo: Phoebe, silvarumque potens Diana (1). D'altra parte, il Carme sec. condivide alcuni aspetti rilevanti con l'“estremo" carme 4, 15, che, nell'ordine della tradizione manoscritta, lo precede (pur essendo successivo per la data di pubblicazione in libro): è "già", infatti, il carme 4, 15 ad aprirsi con Apollo, ma al nominativo (Phoebus volentem proelia me loqui [1]), ed anche il Carme sec., come il carme 4, 15, si chiude con il "canto" (l'inno per Febo e Diana): ...doctus et Phoebi et Dianae/dicere laudes (75-76).

\section{RIASSUNTI}

Orazio ha disposto con notevole cura l'ordinamento dei componimenti lirici che incluse nella raccolta dei Carmina. Questa affermazione, generalmente condivisa dagli studiosi e ben sostenuta da alcune evidenti riprove, merita di essere approfondita. In special modo è parso necessario il tentativo di individuare alcune costanti che rendano riconoscibili i criteri editoriali seguiti dal poeta. Come già nelle Satire e negli Epodi, e nel modello virgiliano delle Bucoliche, particolarmente significativa in proposito è apparsa la decina. Si osservano infatti all'interno della raccolta veri e propri 'confini decimali', identificati dalla ricorrenza di specifici nessi metrico-tematici. Le forme di ordinamento editoriale, che Orazio dovette aver appreso dalle edizioni alessandrine dei lirici (oltre che dai grandi autori ellenistici come Callimaco), 
collaborano all' espressione poetica: da esse il lettore è stimolato a confrontare e riconoscere, a operare dei nessi, a notare delle discontinuità - a costruire insomma, guidato dall'autore,la propria interpretazione dei Carmina, che gli si rivelano essere un'articolata orchestrazione discorsiva (e non una meccanica ed inerte aggregazione di singoli componimenti). Il tema della divinità come forza ordinatrice, contrapposta all'irrazionalità incontrollata della tempesta, si mostra particolarmente adatto ad occupare i luoghi editorialmente esposti della raccolta: a partire dagli inizi del canto (i proemii e le sequenze iniziali), passando per i confini editoriali interni ai singoli libri, per giungere fino ai carmi che occupano, nel singolo libro e nell'insieme della raccolta, le sequenze finali. Parole chiave: ordinamento, struttura editoriale, libro poetico, edizione ellenistica, inizio, proemio, inno, confine editoriale, epilogo, congedo, sequenza decimale, omometria, eterometria, divinità, tempesta, meteorologia, simposio/convito.

\section{INDICE}

Mots-clés : Orazio, Carmina, Alceo, tempesta, Dioscuri

\section{AUTORE}

\section{ANDREA CUCCHIARELLI}

Università di Roma, "La Sapienza" 